\title{
Tritium Management Loop Design Status
}

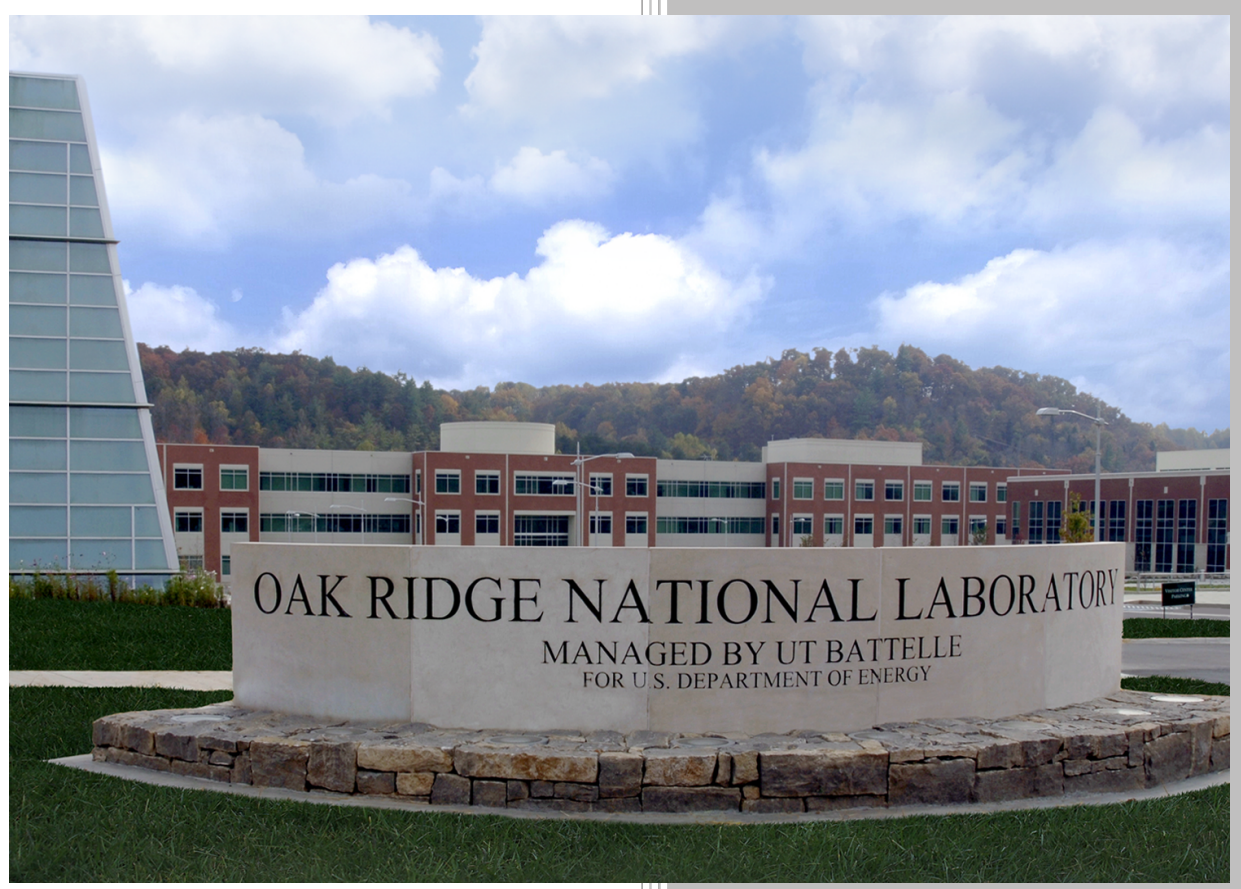

\section{Approved for public release. Distribution is unlimited.}
J. D. Rader
D. K. Felde
J. McFarlane
M. S. Greenwood
A. L. Qualls
P. Calderoni, INL

December 2017 


\section{DOCUMENT AVAILABILITY}

Reports produced after January 1, 1996, are generally available free via US Department of Energy (DOE) SciTech Connect.

Website: http://www.osti.gov/scitech/

Reports produced before January 1, 1996, may be purchased by members of the public from the following source:

National Technical Information Service

5285 Port Royal Road

Springfield, VA 22161

Telephone: 703-605-6000 (1-800-553-6847)

TDD: $703-487-4639$

Fax: 703-605-6900

E-mail: info@ntis.gov

Website: http://classic.ntis.gov/

Reports are available to DOE employees, DOE contractors, Energy Technology Data Exchange representatives, and International Nuclear Information System representatives from the following source:

Office of Scientific and Technical Information

PO Box 62

Oak Ridge, TN 37831

Telephone: $865-576-8401$

Fax: 865-576-5728

E-mail: report@osti.gov

Website: http://www.osti.gov/contact.html

This report was prepared as an account of work sponsored by an agency of the United States Government. Neither the United States Government nor any agency thereof, nor any of their employees, makes any warranty, express or implied, or assumes any legal liability or responsibility for the accuracy, completeness, or usefulness of any information, apparatus, product, or process disclosed, or represents that its use would not infringe privately owned rights. Reference herein to any specific commercial product, process, or service by trade name, trademark, manufacturer, or otherwise, does not necessarily constitute or imply its endorsement, recommendation, or favoring by the United States Government or any agency thereof. The views and opinions of authors expressed herein do not necessarily state or reflect those of the United States Government or any agency thereof. 
Reactor \& Nuclear Systems Division Nuclear Security \& Isotope Technology Division

\title{
Tritium Management Loop Design Status
}

\author{
Authors: \\ J. D. Rader \\ D. K. Felde \\ J. McFarlane \\ M. S. Greenwood \\ A. L. Qualls \\ P. Calderoni, INL
}

Date Published: December 2017

\author{
Prepared by \\ OAK RIDGE NATIONAL LABORATORY \\ Oak Ridge, TN 37831-6283 \\ managed by \\ UT-Battelle, LLC \\ for the \\ US DEPARTMENT OF ENERGY \\ under contract DE-AC05-00OR22725
}





\section{CONTENTS}

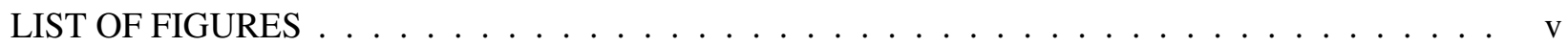

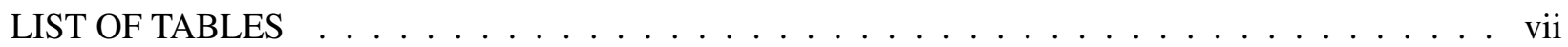

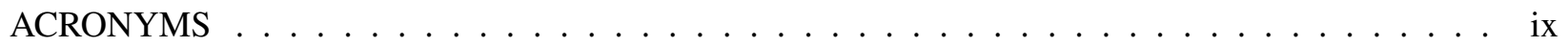

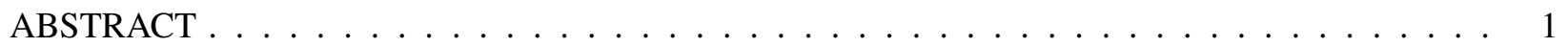

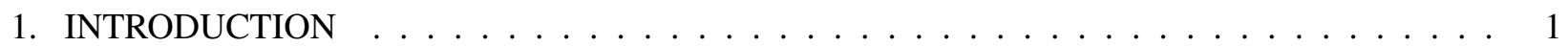

2. TRITIUM LIFECYCLE BEHAVIOR AND REACTOR CHEMISTRY CONTROL . . . . . . . 3

2.1 Tritium Production $\ldots \ldots \ldots \ldots \ldots \ldots$

2.2 Tritium Speciation Calculations $\ldots \ldots \ldots \ldots \ldots \ldots \ldots$

3. PROPOSED TESTING TO MEET OBJECTIVES . . . . . . . . . . . . . . . . . 7

3.1 Static Tests: Phase 1 Task Definitions _ . . . . . . . . . . . . . . . . . 7

3.1.1 Task 1: Investigate the use of LiT as tritium source for the test loop . . . . . . . . . 7

3.1.2 Task 2: Tritium adsorption in FLiBe/getter systems at different redox conditions . . . 7

3.1.3 Task 3: Development of sensors to measure tritium concentration in FLiBe . . . . 8

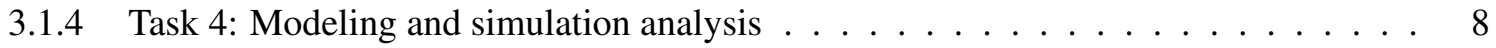

3.2 Flow Tests: Phase 2 Task Definitions . . . . . . . . . . . . . . . . . . . . . . 9

3.2.1 Task 1: Tritium Test Assembly Design for ORNL Loop . . . . . . . . . . . . . . . . 9

3.2.2 Task 2: Detailed Loop Design and Fabrication . . . . . . . . . . . . . . . . . . . 12

4. DESIGN CALCULATIONS . . . . . . . . . . . . . . . . . . . . . 19

4.1 Loop Pressure Drop Scoping Evaluation . . . . . . . . . . . . . . . . . . . . . . 19

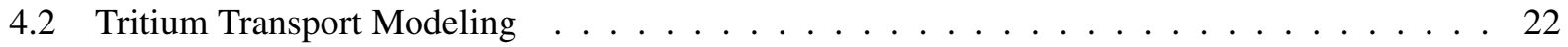

4.2.1 Model Comparison with Analytical Results . . . . . . . . . . . . . . . . 22

4.3 Modeling of Test Loop . . . . . . . . . . . . . . . . . . . . . . . . . . 29

4.4 Planned Analysis . . . . . . . . . . . . . . . . . . . . . . . . . . . 29

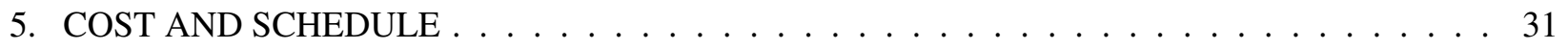

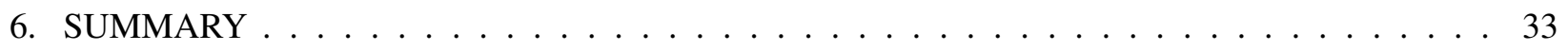

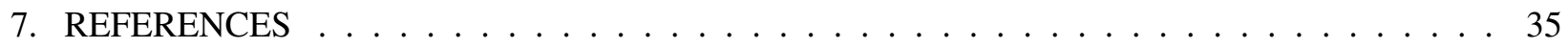

APPENDIX A. Binary Gas Diffusion . . . . . . . . . . . . . . . . . . . A-1

APPENDIX B. Derivation of Axial Tritium Distribution for Molten Salt Application . . . . . . . B-1 



\section{LIST OF FIGURES}

1 Tritium speciation. . . . . . . . . . . . . . . . . . . . . . 6

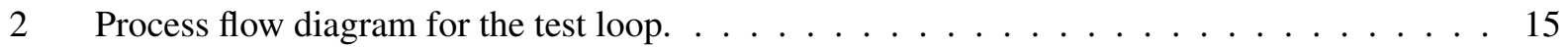

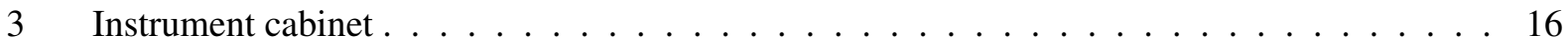

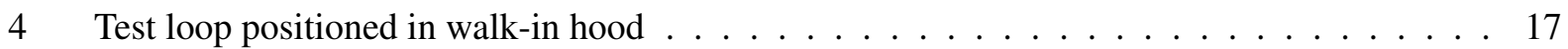

5 Flow loop schematic . . . . . . . . . . . . . . . . . . . 19

6 Comparison of the total loop pressure drop as a function of flowrate at $700^{\circ} \mathrm{C} \ldots \ldots 20$

7 Comparison of loop pressure drop as a function of flowrate at two temperatures using

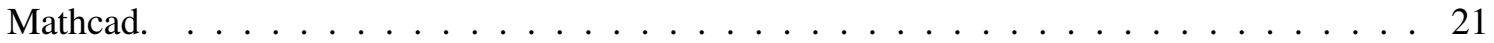

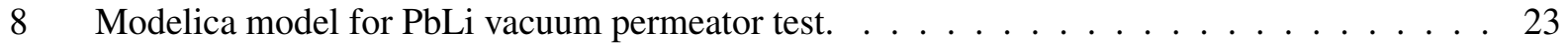

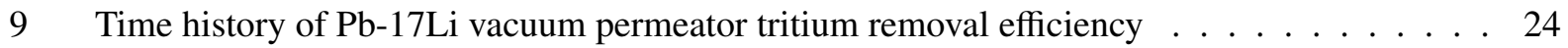

10 Axial tritium distribution at three radial locations for PbLi permeator test . . . . . . . . . 25

11 Modelica model for FLiBe vacuum permeator test. . . . . . . . . . . . . . 26

12 Time history of FLiBe vacuum permeator tritium removal efficiency . . . . . . . . . . 27

13 Axial tritium distribution at three radial locations for FLiBe permeator test . . . . . . . . . 28

14 Modelica model for test loop . . . . . . . . . . . . . . . . . . . . . . . 29

15 Tritium management project schedule - Phase $1 \& 2 \ldots \ldots \ldots \ldots \ldots$ 



\section{LIST OF TABLES}

1 Calculation of tritium injection to represent equilibrium conditions $\ldots \ldots \ldots$

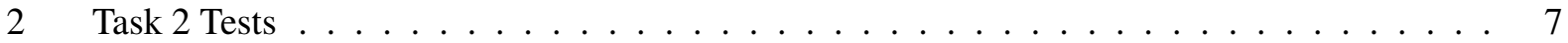

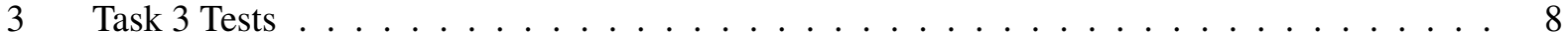

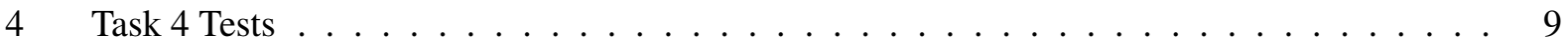

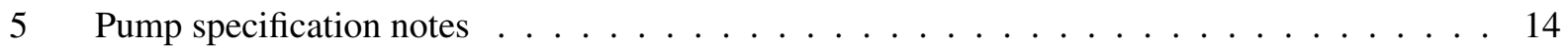

6 Pressure losses in molten salt flow loop at $1.9 \mathrm{~L} / \mathrm{s}(30 \mathrm{gpm})$ and $700^{\circ} \mathrm{C} \ldots \ldots$. . . . . . . 19

7 Pressure losses in molten salt flow loop at $0.95 \mathrm{~L} / \mathrm{s}(15 \mathrm{gpm})$ and $700^{\circ} \mathrm{C} \ldots \ldots \ldots$

8 Radial tritium distribution for $\mathrm{Pb}-17 \mathrm{Li}$ comparison $\ldots \ldots \ldots \ldots$

9 Comparison of $\mathrm{PbLi}$ analytical results to present model . . . . . . . . . . . . . . . 24

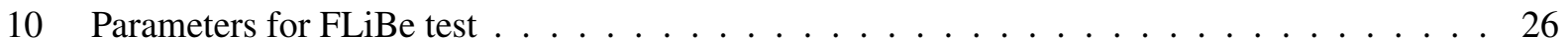

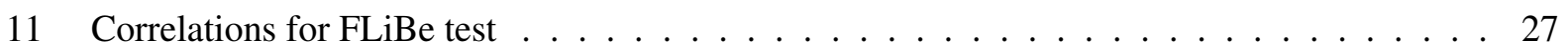

12 Radial tritium distribution for FLiBe comparison . . . . . . . . . . . . . . 28

13 Comparison of FLiBe analytical results to present model . . . . . . . . . . . . 28

14 Parameters for binary gas mass diffusion calculation $\ldots \ldots \ldots \ldots \ldots \ldots$ 



\section{ACRONYMS}

CSTF Coolant Salt Test Facility

ESV emergency shutoff valve

FHR fluoride salt high temperature reactor

FLiBe $\quad \mathrm{LiF}_{-} \mathrm{BeF}_{2}$

FLiNaK LiF-NaF-KF

MWth megawatts-thermal

MSRE Molten Salt Reactor Experiment

ORNL Oak Ridge National Laboratory

PB pebble bed

PFD process flow diagram

PHTS primary heat transfer system

P\&ID process and instrumentation diagram

PID proportional-integral-derivative

PLC programmable logic controller

PNNL Pacific Northwest National Laboratory

RAFM reduced activation ferritic martensitic

RHS right-hand side 



\begin{abstract}
This report summarizes physical, chemical, and engineering analyses that have been performed to support development of a test loop to study tritium migration in FLiBe $\left(2 \mathrm{LiF}_{-} \mathrm{BeF}_{2}\right)$ salts. The loop will operate under turbulent flow, and a schematic of the apparatus has been used to develop a model in Mathcad to suggest flow parameters that should be targeted in loop operation. The introduction of tritium into the loop has been discussed, as well as various means to capture or divert the tritium from egress through a test assembly. Permeation was calculated, starting with the development of a Modelica model for a transport through a nickel window into a vacuum, followed by modification of the model for a FLiBe system with an argon sweep gas on the downstream side of the permeation interface. Results suggest that tritium removal with a simple tubular permeation device will occur readily. Although this system is idealized, it suggests that rapid measurement capability in the loop may be necessary to study and understand tritium removal from the system.
\end{abstract}

\title{
1. INTRODUCTION
}

The relatively large production rate of tritium in molten salt reactors is a primary challenge for deployment of this reactor type, and methods to manage tritium disposition must be developed to limit the release of tritium to the environment. At the high operating temperature of molten salt reactors, tritium can penetrate metal boundaries. This is problematic in the primary-to-intermediate loop heat exchanger of proposed reactor designs because it creates a potential pathway to the environment.

It is considered important to develop and demonstrate both redox control capability and specific tritium capture methods prior to moving to larger scale systems. Redox control in the fluoride salt-based system will control the form of tritium and will therefore impact the release rates. Therefore, the underlying mechanisms must be understood in designing tritium capture methods.

The tritium management project is divided into two phases that are intended to lay the groundwork for an engineering scale facility. Static capsule tests in Phase 1 will examine materials and compatibility issues and inform the design of test assemblies for the flow tests in Phase 2. It is also considered important to simulate reactor-like tritium concentrations in the appropriate form, so a second goal of the Phase 1 effort will be to produce a lithium tritide (LiT) pellet as a means to introduce tritium into the flow loop of Phase 2 .

The Phase 2 tests will provide a platform for examining tritium capture methods in a flowing system with turbulent flow conditions and associated mixing and concentration gradients. The smaller scale of these tests will allow for comparison of different methods and down-select for use in the engineering scale facility. Additionally, the development and proof-testing of tritium measurement techniques and in-situ measurement and control of the redox condition of the salt will provide a basis for design of similar systems in the engineering scale facility.

This report includes a section on tritium lifecycle behavior and reactor chemistry control, providing a basis for the planned experimental work. This is followed by a more detailed description of the proposed testing in Phases 1 and 2, including a description of the flow test loop.

The proposed test loop is then analyzed using computer models. Both thermal-hydraulic and trace substance transport modeling has been developed. Simultaneous calculation for the molten salt pressure-temperature fields and tritium transport/speciation solution is possible using the unified models 
demonstrated. The developed models are compared to analytical solutions and other codes if applicable as a preliminary verification to their fidelity and performance. 


\section{TRITIUM LIFECYCLE BEHAVIOR AND REACTOR CHEMISTRY CONTROL}

\subsection{Tritium Production}

Scaling of the tritium mitigation experiment will require an estimate of the amount of tritium to be introduced, which will be based on (a) the steady state introduction of a flowing mixture of T2 gas or (b) addition of LiT. In either case, a steady-state concentration will be established in the pumped loop bypass section before introducing flow to the test section.

Parameters for calculations of equilibrium tritium production are provided from the thesis work of Stempien [1]. The analysis of tritium production is based on a $236 \mathrm{MWth}$ Mk1 PB-FHR. The $6 \mathrm{~L}$ experimental loop to be built at ORNL, which is described in more detail later in this report, will have a 2.5 L bypass that can be charged with tritium before allowing the salt to flow to the test assembly. If it is assumed that the $6 \mathrm{~L}$ test loop will scale with the primary heat transport system (PHTS) of Mk1 (46.82

$\mathrm{m}^{3}$ ), the volumetric scaling factor is 7,800. At the beginning of a run, tritium will be introduced into the 2.5 L loop bypass, where a steady-state concentration will be established. The test assembly will be isolated from the bypass, so the concentration of tritium in the bypass loop must be greater than that required for loading the complete assembly $(6 \mathrm{~L} / 2.5 \mathrm{~L})$ by a factor of $2.4 \mathrm{~g}$ to give the desired concentration in the complete loop. In Table 1 below, details of Mk1 are given in column 2. The tritium loading required to scale the 6 L ORNL loop to the Mk1 PHTS is shown in column 3, which dictates the tritium loading in the bypass loop, shown in column 4 . Note that these idealized calculations assume that losses during introduction of tritium are minimal, that equilibrium is quickly established, and factors such as flow rate and surface/volume ratio have no effect on equilibrium concentration. Thus, the injection rate to reproduce steady state conditions is estimated as $\sim 4 \mathrm{mCi} / \mathrm{h}$.

Table 1. Calculation of tritium injection to represent equilibrium conditions

\begin{tabular}{llll}
\hline & $\begin{array}{l}\text { Mk1 (PHTS } \\
\text { Loop) }\end{array}$ & $\begin{array}{l}\text { ORNL loop including } \\
\text { test assembly scaled } \\
\text { wrt Mk1 PHTS }\end{array}$ & $\begin{array}{l}\text { ORNL loop bypass, } \\
\mathbf{2 . 4 x ~ m o r e ~ t r i t i u m ~} \\
\text { than complete loop }\end{array}$ \\
\hline Volume $\left(\mathrm{m}^{3}\right)$ & 46.82 & $6 \times 10^{-3}$ & $2.5 \times 10^{-3}$ \\
Power $(\mathrm{MWth})$ & 236 & 0 & 0 \\
Equilibrium T production $(\mathrm{Ci} / \mathrm{d})$ & 692 & $\mathrm{n} / \mathrm{a}$ & $\mathrm{n} / \mathrm{a}$ \\
Volumetric T production $\left(\mathrm{atom} \mathrm{T} / \mathrm{m}^{3}-\mathrm{s}\right)$ & $3.5 \times 10^{15}$ & $3.5 \times 10^{15}$ & $8.4 \times 10^{15}$ \\
Production or injection $(\mathrm{mol} \mathrm{T} / \mathrm{s})$ & $2.7 \times 10^{-7}$ & $3.5 \times 10^{-11}$ & $3.5 \times 10^{-11}$ \\
T production or Injection $(\mathrm{Ci} / \mathrm{h})$ & $2.9 \times 10^{1}$ & $3.7 \times 10^{-3}$ & $3.7 \times 10^{-3}$ \\
\hline
\end{tabular}

Conversion factors used in the calculations are:

1: $1 \mathrm{~mol}$ tritium $=29263.8 \mathrm{Ci} ; 3.59 \times 10^{14} \mathrm{~Bq} / \mathrm{g}$

2: Molar mass tritium $=3.016 \mathrm{~g} / \mathrm{mol}$

An alternative method of tritium injection is to add a pellet of LiT (molar mass of $\sim 10 \mathrm{~g} / \mathrm{mol}$ ) into the bypass loop and allow it to dissolve into the salt. Over a 24-hour period, the amount of tritium to be injected (based on the analysis above) will be as much as $89 \mathrm{mCi}$, or $3.0 \times 10^{-6} \mathrm{~mol} \mathrm{~T}$. This corresponds to $\sim 30 \mu \mathrm{g}$ of LiT.

The equilibrium calculations give a minimum in the total tritium inventory in the loop, as they do not account for tritium retained in the salt or on structural surfaces. Tritium concentrations in the salt can be calculated if the chemical potential of the salt is known, assuming thermodynamic equilibrium. Graphite 
can have an uptake of $15 \%$ of the total inventory of tritium produced, as $\mathrm{T}_{2}$ and $\mathrm{TF}$, mainly on the surface of the outer pyrolytic carbon layer. Although the Coolant Salt Technology Facility (CSTF) experiment at ORNL [2] indicated that the system had to be "passivated" before an equilibrium experiment could be carried out, interaction of fluoride with metal surfaces in the reactor does not form a passivation layer. The role of these interactions on the salt chemistry must be explored in the static and flowing experimental salt systems.

\subsection{Tritium Speciation Calculations}

Tritium can be added to the loop either in the form of $\mathrm{T}_{2}$ gas or as LiT, as mentioned previously. The addition of a small amount of LiT to the salt is not going to affect the chemical potential, expressed as $\Delta G_{\mathrm{F} 2}$ in [1]. Hence, the expression for fluorine potential formulated by Stempien can be used, defined by the equilibrium (1), and the expression for the standard Gibbs free energy as calculated by Stempien using HSC Chemistry, (2). The units of $\Delta G_{\mathrm{TF}}^{0}$ are $\mathrm{kJ} / \mathrm{mol} \mathrm{TF}$. Temperature, $\mathrm{T}$, is in $\mathrm{K}$.

$$
\begin{gathered}
\mathrm{T}_{2}+\mathrm{F}_{2} \rightarrow 2 \mathrm{TF} \\
\Delta G_{\mathrm{TF}}^{0}=-4.6976 \times 10^{-10} T^{3}+3.1425 \times 10^{-6} T^{2}-8.8612 \times 10^{-3} T-2.7305 \times 10^{2}
\end{gathered}
$$

At $650^{\circ} \mathrm{C}, \Delta G_{T F}^{0}$ is $-278.589 \mathrm{~kJ} / \mathrm{mol} \mathrm{TF}$. For an FHR, the equilibrium governing the dissolution of LiT (3) may be governed by $\mathrm{HF} / \mathrm{H}_{2}$ in contact with the salt (4). $P_{T F}$ and $P_{T_{2}}$ are the fractional partial pressures of $\mathrm{TF}$ and $\mathrm{T}_{2}$, and $\mathrm{R}$ is the gas constant in units of $8.314 \mathrm{~J} / \mathrm{mol}-\mathrm{K}$.

$$
\begin{gathered}
\mathrm{LiT}+\mathrm{TF} \leftrightarrow \mathrm{LiF}+\mathrm{T}_{2} \\
\Delta G_{\mathrm{F}_{2}}=2 R T \ln \left(\frac{P_{\mathrm{TF}}}{\sqrt{P_{\mathrm{T}_{2}}}}\right)+2 \Delta G_{\mathrm{TF}}^{0}
\end{gathered}
$$

Thus, given the fluorine chemical potential, the ratio of TF to $\mathrm{T}_{2}$ can be determined, or vice versa. In this particular calculation, the ratio of $P_{\mathrm{TF}}$ and $P_{\mathrm{T}_{2}}$ was determined for several redox potentials ranging from -660 to $-720 \mathrm{~kJ} / \mathrm{mol} \mathrm{F}_{2}$ at $650^{\circ} \mathrm{C}$. The partial pressure of TF to $\mathrm{T}_{2}$ can be determined knowing the Henry's law coefficients for $\mathrm{TF}$ and $\mathrm{T}_{2}$, equations $(5,6)$ and substituting them into equations $(7,8)$ to determine the concentrations in the molten salt phase. The units of the Henry's law constants are $\mathrm{mol} / \mathrm{m}^{3}-\mathrm{Pa}$, and the temperature coefficient, $t$, is in units of ${ }^{\circ} \mathrm{C}$. Molten salt concentrations can be determined by solving Eq. (9) as a quadratic equation, giving two roots, one of which leads to a negative concentration and is therefore unphysical. In this expression, $\mathrm{c}_{\text {total }}$ is the total concentration of tritium introduced into the system, $30 \mu \mathrm{g}$ of LiT or $3 \times 10^{-4} \mathrm{~mol} / \mathrm{m}^{3}$, as discussed earlier. With these results, the equilibrium for Eq. (3) is completely determined based on the equilibrium constant expression for Eq. (3), as shown in Eq. (10), and the determination of $\Delta G_{\mathrm{LiT}+\mathrm{TF}}^{0}$ in Eq. (11). Note that except for LiF, concentrations are being used instead of activities in Eq. (11), an assumption that has been used with other fluoride salt solutes. This probably causes little error for the low concentration species: $\mathrm{T}_{2}$, LiT, and TF. Activities for $\mathrm{LiF}$ in the eutectic have been determined by Holm [3, 4] and more recently by Romero-Serrano et al. [5]. 


$$
\begin{gathered}
k_{\mathrm{TF}, \mathrm{FLiBe}}=0.001707 \mathrm{exp}-0.00426 t \\
k_{\mathrm{T}_{2}, \mathrm{FLiBe}}=2.714 \times 10^{-8} \exp -0.004235 t \\
c_{\mathrm{TF}}=k_{\mathrm{TF}, \mathrm{FLiBe}} P_{\mathrm{TF}} p_{\text {total }} \\
\frac{c_{\mathrm{T}_{2}}=k_{\mathrm{T}_{2}, \mathrm{FLiBe}} P_{\mathrm{T}_{2}} p_{\text {total }}}{\sqrt{P_{\mathrm{TF}}}}=\frac{c_{\text {total }}-2 c_{\mathrm{T}_{2}}}{p_{\text {total }} k_{\mathrm{TF}, \mathrm{FLiBe}}} \\
\sqrt{\frac{c_{\mathrm{T}_{2}}}{p_{\text {total }} k_{\mathrm{T}}, \mathrm{FLiBe}}}=\exp \frac{\Delta G_{\mathrm{F}_{2}}-2 \Delta G_{\mathrm{TF}}^{0}}{2 R T} \\
K_{\mathrm{LiT}+\mathrm{TF}}=\frac{a_{\mathrm{LiF}}\left[\mathrm{T}_{2}\right]}{[\mathrm{LiT}][\mathrm{TF}]} \\
\Delta G_{\mathrm{LiT}+\mathrm{TF}}^{0}=\Delta G_{f, \mathrm{LiF}, \mathrm{FLiBe}}^{0}+\Delta G_{f, \mathrm{TH}}^{0}+\Delta G_{f, \mathrm{LiH}}^{0}+\Delta G_{f, \mathrm{HF}}^{0}
\end{gathered}
$$

Thermodynamic data for $\mathrm{LiH}, \mathrm{LiF}$, and $\mathrm{HF}$ are available from JANAF [6]. The graph below (Fig. 1a) replicates the Stempien graph, 3.16, based on the equilibrium $\mathrm{LiH}+\mathrm{HF} \leftrightarrow \mathrm{LiF}+\mathrm{H}_{2}$. The $\mathrm{H}$ replaces $\mathrm{T}$ for this calculation. The partial excess Gibbs free energy of LiF in the molten salt has been reported by Holm [3] at $862^{\circ} \mathrm{C}$ as:

$$
G_{\mathrm{LiF}}^{E}=\left(-15.527-90.245 X-114.198 X^{2}\right) X^{2}
$$

For LiF in FLiBe at a mole fraction, $X$, of 0.667, from Holm and Romero-Serrano [3] and [5], one can calculate an activity coefficient of 0.91 . For the purposes of the calculation, the chosen redox potential sets the ratio of the partial pressures of $\mathrm{T}_{2}$ and $\mathrm{TF}$ in contact with the salt. From there, one can calculate the dissolved $\mathrm{T}_{2}$ and TF based on Henry's law coefficients. The dissolved concentrations $\mathrm{T}_{2}$ and $\mathrm{TF}$ are given in the second plot (Fig. 1b). The partial pressures of $\mathrm{T}_{2}$ and TF over the salt are low (ranging from $6 \times 10^{-3}$ to $1 \times 10^{-4}$, and $2 \times 10^{-6}$ to $4 \times 10^{-5}$ atm respectively), assuming $p_{\text {total }}=101325 \mathrm{~Pa}$. The redox potential could be set by introducing a non-tritiated $\mathrm{H}_{2} / \mathrm{HF}$ mixture, or a couple based on a multivalent metal fluoride. At $650^{\circ} \mathrm{C}$ and at reducing conditions (MSRE operated at $-700 \mathrm{~kJ} / \mathrm{mol}$ ) the equilibrium is pushed way over to the right, meaning that $\mathrm{LiF}$ and $\mathrm{T}_{2}$ are more stable than $\mathrm{LiT}$ and $\mathrm{TF}$. The $\mathrm{LiF}$ was assumed to be set by the salt concentration and not to change, so any change in concentration of LiT is related to the $\mathrm{T}_{2} / \mathrm{TF}$ equilibrium. Data that are missing that would improve this calculation are free energies of mixing for $\mathrm{LiF} / \mathrm{BeF}_{2}$, thermodynamic data for $\mathrm{TF}$ and $\mathrm{T}_{2}$, and solubility data for $\mathrm{LiH}$ or $\mathrm{LiT}$ in FLiBe. 


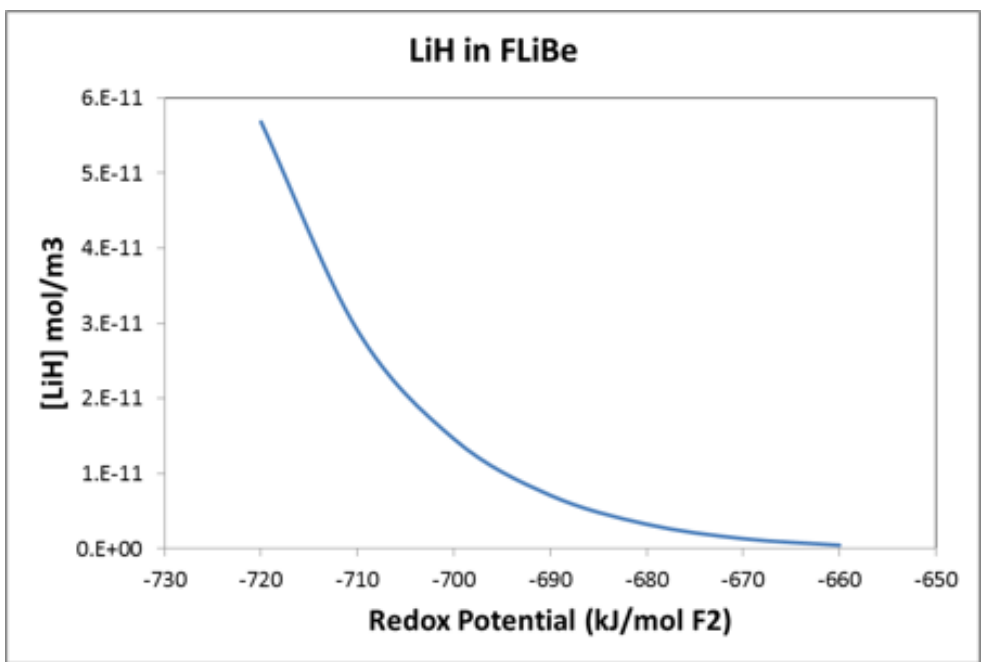

(a) $\mathrm{LiH}$ in $\mathrm{FLiBe}$

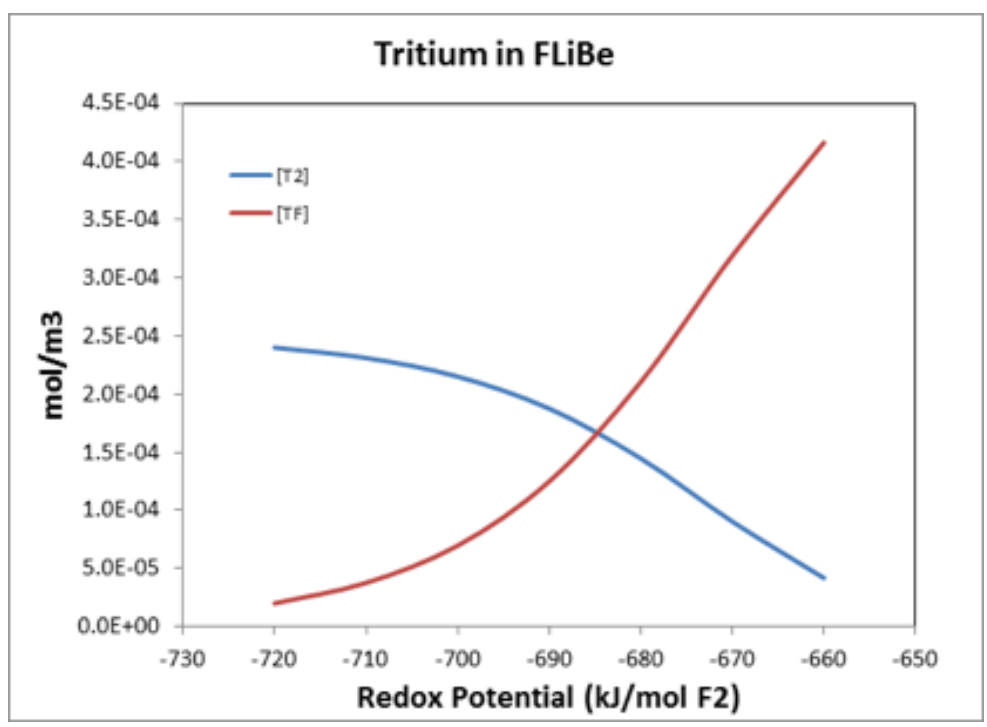

(b) Tritium in FLiBe

Figure 1. Tritium speciation. 


\section{PROPOSED TESTING TO MEET OBJECTIVES}

The objective of Phase 1 is to provide information in support of the design and operation of the flow loop. A breakdown of the tasks is provided below. This is followed by a discussion of the test assemblies and capture methods proposed for testing in the flow loop of Phase 2.

\subsection{Static Tests: Phase 1 Task Definitions}

\subsubsection{Task 1: Investigate the use of LiT as tritium source for the test loop}

As it is not feasible to generate tritium in situ by transmutation, the current design of the loop includes an injection system based on a thin-walled, closed-ended nickel tube that is pressurized with a mixture of inert gas and $\mathrm{T}_{2}$ [2]. This system was used in a tritium test loop as part of the MSRE program. While proven and reliable, it has several disadvantages, including a slow response time and the fact that tritium is injected from a metal/liquid interface rather than generated in the liquid bulk, which better simulates in-core conditions. There are plans to investigate whether the rapid dissolution of LiT could be an alternative method to provide a controlled T concentration in the liquid bulk. Scoping calculations show that the hydride is highly unstable in the salt at the reference temperature, but the method to fabricate LiT and its use as a tritium source should be validated by scoping experiments.

\subsubsection{Task 2: Tritium adsorption in FLiBe/getter systems at different redox conditions}

The solubility of hydrogen isotopes in fluoride salt depends on the redox condition of the system, because this determines whether the isotopes of hydrogen $(\mathrm{H}, \mathrm{D}, \mathrm{T})$ are present in elemental form (e.g., $\left.\mathrm{H}_{2}\right)$ or as HF. The activities for this project will focus on a comparative analysis of adsorption in different crucible/FLiBe/getter systems under controlled redox conditions. Redox control is established by flowing different mixtures of $\mathrm{H}_{2} / \mathrm{HF}$ in an Ar purge above the melt. This is also planned for the loop experiments. $\mathrm{T}_{2}$ gas will be added to the flowing mixture, effectively establishing a controlled concentration of HT. The precise determination of transport properties will not be an objective of this task, as this will be a function of the loop conditions. However, the kinetics of sorption and desorption will be analyzed to determine how they affect tritium migration in the absence of flow as a baseline case. Tests to be carried out will be complementary to those at the University of Wisconsin [7].

Table 2. Task 2 Tests

\begin{tabular}{lll}
\hline & 2.1 & $\mathrm{Ni} / \mathrm{FLiBe}$ \\
& 2.2 & $\mathrm{Ni} / \mathrm{FLiBe} /$ Nuclear graphite \\
$\mathrm{D}_{2}$ Tests (1 year) & 2.3 & $\mathrm{Ni} / \mathrm{FLiBe} /$ Nickel coated metallic getter particles \\
& 2.4 & $\mathrm{Ni} / \mathrm{FLiBe} / \mathrm{C}$ getters (high porosity, high denisty foams, etc) \\
& 2.5 & $\mathrm{Ni} / \mathrm{FLiBe} /$ proton conducting membrane \\
\hline & 2.6 & $\mathrm{Ni} / \mathrm{FLiBe}$ \\
$\mathrm{T}_{2}$ Test (6 months) & 2.7 & $\mathrm{Ni} / \mathrm{FLiBe} /$ Nuclear graphite \\
& 2.8 & $\mathrm{Ni} / \mathrm{FLiBe} /$ Nickel coated metallic getter particles \\
& 2.9 & $\mathrm{Ni} / \mathrm{FLiBe} / \mathrm{C}$ getters (high porosity, high density foams, etc).
\end{tabular}

Getter materials are discussed in Sec. 3.2.1. Provisions must be considered to allow post-experiment analysis of the getter materials (removal of salt from crucibles, removal of salt residues by acid cleaning, 
etc). In the first phase of testing, $\mathrm{D}_{2}$ will be used instead of $\mathrm{T}_{2}$, in concentrations high enough to allow its discrimination. This will simplify handling and supporting analysis. The preliminary matrix for tests is provided in Table 2.

\subsubsection{Task 3: Development of sensors to measure tritium concentration in FLiBe}

The development of sensors capable of measuring the local concentration of tritium in FLiBe would substantially increase the accuracy of the performance assessment to be conducted in the flow loop. Sensor fabrication activities are included in the scope. The sensor test matrix is provided in Table 3.

Table 3. Task 3 Tests

\begin{tabular}{lll}
\hline Sensor tests (1 year) & 3.1 & Permeation sensor (nickel membrane) \\
& 3.2 & Electrochemical sensor (impedance spectroscopy)
\end{tabular}

A permeation cell with a nickel window has been described previously by Calderoni et al. [8] The cell, which is designed to operate at molten salt temperatures of $500-700^{\circ} \mathrm{C}$, measures the concentration of tritium above the molten salt surface from $0.1 \mathrm{ppm}$ to $10 \%$. The cell can either be used to inject tritium into the salt from a gas stream $\left(4 \mathrm{~cm}^{3} / \mathrm{min} \mathrm{Ar} / \mathrm{H}_{2}\right)$ or to remove tritium from the salt for monitoring (into a flow of $20 \mathrm{~cm}^{3} / \mathrm{min} \mathrm{Ar} / \mathrm{H}_{2}$ ). One key aspect of the permeation cell design is a nickel-200 plate window through which tritium will readily diffuse. In Calderoni's work, the sweep gas transported diffused tritium to a sampling system that included a quadrupole mass spectrometer and a gas chromatograph equipped with a proportional counter.

An electrochemical sensor for online monitoring of fluoride chemical potential is now under development, and fundamental work in this area would contribute to Task 3 of this proposed scope of work. Anodic stripping voltammetry has been used to measure dissolved chromium in FLiNaK salts and can be used to monitor trace metals at concentrations as low as $1 \mathrm{ppm}$ [9]. In this work at the University of Wisconsin, working, counter, and reference electrodes were all made from platinum wire. Although the electrodes were immersed in the salt, an accompanying thermocouple was located in a headspace formed by an alumina apparatus. Such an assembly would require modification for FLiBe salts because of the solubility of $\mathrm{Al}_{2} \mathrm{O}_{3}$. A collaboration of Pacific Northwest Nuclear Laboratory (PNNL) and University of Cincinnati [10] used cyclic voltammetry to investigate europium redox couples in chloride salts. As these are active areas of research, it is expected that a collaboration will be encouraged to use the ORNL loop as a test bed for molten salt electrochemical measurements.

\subsubsection{Task 4: Modeling and simulation analysis}

Modeling and simulation analysis are performed in support of Tasks 2 and 3. The main objectives are given in Table 4.

Modeling is discussed in Sec. 4. Several modeling tools were assessed, including TMAP [11] and TRIDENT [1]. It was determined that a unified simulation tool could be developed in the Modelica environment. While the development is not complete, the foundation for a complete modeling solution has been laid. 
Table 4. Task 4 Tests

\begin{tabular}{lll}
\hline 4.1 & $\begin{array}{l}\text { Support to the design development of the test cells } \\
\text { (Task 2) and permeation sensor (Task 3), as well } \\
\text { as the definition of test parameters (temperature, } \\
\text { pressure, flow, input tritium concentration, etc.) } \\
\text { Modeling and }\end{array} 4.2 \begin{array}{l}\text { Support to data analysis for the evaluation of } \\
\text { transport properties and the impact of parasitic ef- } \\
\text { fects (permeation losses, adsorption in structural } \\
\text { components, etc.) }\end{array}$
\end{tabular}

\subsection{Flow Tests: Phase 2 Task Definitions}

\subsubsection{Task 1: Tritium Test Assembly Design for ORNL Loop}

The goal of the tritium mitigation operation is to keep the partial pressure of tritium below $0.05 \mathrm{~Pa}$ in the primary circuit to prevent removal through the heat exchangers. Test sections will be created that can be interchanged on the pumped loop. Tritium mitigation by sorption (adsorption, absorption, and chemisorption) will be investigated. Permeation through membranes will also be tested. Both sorption and permeation rates are dependent on the diffusion of tritium to the capturing material and adsorption onto the material surface. In permeation, absorption into the material is the step after adsorption, followed by diffusion through the barrier, release from the other side of the barrier, and diffusion into the recovery fluid. Tritium barriers will not be credited in these tests, although a tungsten coating may be used to minimize loss outside of the test section.

We have considered five configurations for the tritium test assembly, in addition to an empty tube: (i) adsorption onto nuclear graphite (pyrolytic carbon), (ii) adsorption onto a high porosity carbon bed, (iii) adsorption on a metallic getter such as $\mathrm{ZrC}$, (iv) permeation through a membrane, such as the diffusion through Ni or Pd coating on a porous support, and (v) permeation through a proton conducting membrane. These are be discussed in more detail below.

(i) Adsorption: nuclear graphite (pyrolytic carbon)

Both $\mathrm{TF}$ and $\mathrm{T}_{2}$ can be removed from the molten salt by graphite [7]. The partial pressure of $\mathrm{T}_{2}$ can be reduced by two orders of magnitude and that of TF by one order of magnitude. Graphite in the reactor will hold up tritium release, but it may take different forms, depending on its properties and configuration. In an FHR, graphite will be present as a coating for fuel particles and also as an assembly for housing the fuel. Pyrolytic carbon layers greatly reduce the permeation of tritium into the graphite. Pebbles like those designed for gas-cooled reactors have no pyrolytic carbon layer, so they will allow tritium to permeate easily. The tritium will move along grain boundaries and become trapped through dissociative chemisorption at edges and grain boundaries.

There are several factors that will affect the adsorption of tritium into the carbon. It is not known if carbon sorption in an FHR is limited by kinetics or solubility. Besides the form of the carbon as discussed earlier, radiation damage to the carbon and radiation flux may affect tritium migration. Radiation lowers hydrogen atom diffusivity in carbon by one or two orders of magnitude, so it would also reduce the rate of tritium capture. The carbon will saturate if it is not recirculated as in a pebble bed reactor, as a loading of 2-10 wppm T/C is needed to maintain a low tritium partial pressure. Saturation will also depend on the 
non-radiolytic hydrogen present. If hydrogen is added to the system to control the redox conditions of the salt, the hydrogen will also adsorb onto carbon, as will the tritium. Under accident conditions, the tritium can be desorbed when temperatures are elevated. The study of carbon materials is being conducted at the University of Wisconsin[7].

(ii) Adsorption: high porosity carbon for adsorption bed

Non-nuclear grade porous carbon (e.g., activated carbon CAL-TR, or Maxsorb MSC-30) may have a specific surface area that is up to 1,000x that of nuclear grade graphite (e.g., IG110U), and results from University of Wisconsin [7] show a hydrogen uptake of close to $5 \mathrm{~cm}^{3} / \mathrm{g}$ at pressures up to $9,000 \mathrm{~Pa}$. Although this material is less stable than nuclear-grade graphite, it could be employed outside the core where fields are much lower. The adsorption beds would likely be prepared as fixed beds for the loop design. Other possibilities for the reactor include a fluidized bed, in which the absorbent is transported with the salt, and a counter current flow moving bed. It would be more difficult to engineer the bed in the latter cases, although the moving bed allows for online regeneration and chemistry control by introduction of a sweep gas $\left(\mathrm{H}_{2} / \mathrm{HF}\right)$.

ORNL has graphite spheres that are $3 \mathrm{~cm}$ in diameter available for bed preparation. These have been made to simulate FHR fuel. They can be packed into a tube configured to give the correct flow rate and pressure drop specified for the loop. Online analysis could be conducted by passing a sweep gas through the test section at the same flow rate/across the same interfacial area as for the other test sections. Analysis of the graphite would be completed post-test by heating and monitoring the gas release of tritium during the regeneration cycle.

(iii) Adsorption: metallic getter ( $\mathrm{ZrC})$

Carbides will be present in the fuel assemblies: $\mathrm{SiC}$ and $\mathrm{ZrC}$. The latter is introduced as a sacrificial layer to absorb excess oxygen generated during fissioning of uranium in $\mathrm{UO}_{2}$. (Porter, Knight et al. 2013) Such carbides may have a role in the sorption of tritium as dissociative chemisorption of hydrogen has been observed for $\mathrm{ZrC}, \mathrm{NbC}$, and $\mathrm{HfC}$ at a specific crystal face (111) [12, 13]; however, retention of tritium requires migration into the material, and that has been shown to be negligible for temperatures above $700^{\circ} \mathrm{C}$ for deuterium implanted into metal carbides [14]. Another key factor is the stability of the carbide in the molten salt. For instance, $\mathrm{ZrC}$ as a getter would have to be more stable than $\mathrm{ZrF}_{4}$ or $\mathrm{Zr}$ under FHR conditions of temperature and fluorine chemical potential. The Gibbs energy of formation for $\mathrm{ZrF}_{4}$ ranges from $-440\left(500^{\circ} \mathrm{C}\right)$ to $-410\left(800^{\circ} \mathrm{C}\right)$. Hence it is not as stable as $\mathrm{BeF}_{2},-455\left(500^{\circ} \mathrm{C}\right)$ to $-430\left(800^{\circ} \mathrm{C}\right)[1]$. The Gibbs energy of formation of $\mathrm{ZrC}$ is much lower than that of $\mathrm{Be}_{2} \mathrm{C}$, so it is likely that if it were introduced as the carbide, $\mathrm{ZrC}$ would be stable and would not affect the chemistry of the molten salt. Except for bench-scale research on the dissociative chemisorption of hydrogen on surfaces, the use of metal-carbide getters does not look promising at FHR operating temperatures. There is discussion in the literature of using carbides to enhance hydrogen transport within composite $\mathrm{Ni}-\mathrm{ZrC}$ electrode materials, but this work has been done at temperatures below $100^{\circ} \mathrm{C}$ [15], well below the range of FHR operation.

(iv) Permeation through a membrane (diffusion through Ni or Pd coating on porous ceramic support)

Hydrogen can reversibly adsorb and dissolve in base metals such as Ni or Pd. The hydrogen (or tritium) will transport through the membrane following the concentration or temperature gradient or both. A permeation membrane placed upstream of a heat exchanger will remove much of the tritium before it encounters the high-surface area heat exchanger, where tritium release can be problematic. The equation for tritium flux, $J$ (atom/s) through a tube of length $L$, outer diameter $d_{o}$, inner diameter $d$, is given by Eq. 
(13) [16]:

$$
J=\frac{2 \pi L}{\ln \left(\frac{d_{o}}{d}\right)} \Phi(T)\left(p_{2}^{x}-p_{1}^{x}\right)
$$

where $\Phi$ is the permeation coefficient of the material, and the term on the RHS of the equation gives the difference in partial pressure from the downstream and upstream side of the membrane, respectively. The exponent $\mathrm{x}$ is experimentally determined and varies from 0.5 to 1.0 , depending on whether the permeation is bulk or surface limited. When $\mathrm{x}$ is 0.5 , the equation becomes a form of Sievert's Law, which states that the concentration of dissolved hydrogen is proportional to the square root of the partial pressure of hydrogen in contact with the surface. If the thickness of the metal layer and the permeation coefficient are known, then the flux of hydrogen through the metal over a given length can be calculated. Film thicknesses of $25 \mu \mathrm{m}$ can be used if support is provided. ITER plans to use Pd-Ag on stainless steel as a means to separate hydrogen, but at lower temperatures than an FHR [17]. This material's permeability is about 3.5 times that of $\mathrm{Ni}$, a structural metal under consideration for FHRs. A ceramic such as alumina can be used as a support, which dissolves in FLiBe salt, but in this case it would be protected by the metal layer. Layered materials with secondary permeation layers can also be used. Cermets, which are a sintered mixture of ceramic and metal, have also been proposed. A drawback of diffusion-controlled permeation is that it depends on the difference in pressure from the upstream and the downstream sides. In the case of low concentrations of tritium in the loop, the permeation flux will be very low.

For ORNL testing, Ni-coated tubing will be tested for permeability to tritium. The thickness of the tubing will be minimal, 10-20 mil (254-508 $\mu \mathrm{m})$. The sorptive Ni layer on the tubing can be made even thinner, 25 $\mu \mathrm{m}$, to improve flux. A number of concentric tubes will be mounted in the larger test-section with a manifold design so that either a sweep gas can be passed inside or outside the tubing or a vacuum can be pulled, thus maintaining a concentration (or partial pressure) drop across the Ni membrane. The sweep gas will be analyzed on-line using ion chamber counters and mass spectrometry. Getters can also be deployed in the stack to give integrated tritium capture, which may be necessary for mass balance calculations.

(v) Permeation: proton conducting (Perovskite on ceramic support/yttria)

To increase flux, other membrane configurations have been considered. With a proton-conducting membrane, $100 \%$ selectivity for hydrogen can be achieved in response to an applied voltage. This is a new technology that was developed for fuel cells and is being considered for fusion applications $[18,19]$. Doped perovskites can be configured as hydrogen pumps [20, 21, 22, 23] and can easily be made by sintering stoichiometric oxides[24, 25, 26, 27]. However, because of the novelty, the technology is not as well developed as technologies for metal-coated membranes. Static testing of the materials in contact with molten salt would be needed before these can be considered for the loop section. Tritium sorption experiments in a non-pumped configuration are also recommended. Deployment of the proton-conducting membrane in the ORNL tritium test loop would be similar to that of the Ni-coated membrane, except that electrical isolation and the ability to add a bias to the membrane would be required. This engineering would be additional scope that could be addressed in a side project beyond the main focus of the tritium extraction tests.

In summary, five configurations were considered for the tritium test assembly, in addition to an empty test section. Some of these methods for tritium separation and trapping use relatively well understood technologies, such as using graphite of different grades as a getter medium. Interaction of hydrogen with 
these materials has been studied, but kinetics of sorption and desorption are still not well understood. Hence, static testing in Phase 1 should focus on kinetic vs capacity limitations for nuclear-grade graphite vs highly porous graphite. Any test plan should be complementary to the study of graphite at the University of Wisconsin. Metal carbides were suggested as a possibile getter material, but literature on the topic indicates that although these materials may superficially adsorb tritium, there is little penetration into the interior. Particularly at FHR operating temperature, metal carbides will not affect the release of tritium into the environment.

Permeation through membranes has also been postulated as a means for removal of tritium from the molten salt. Expressions have been developed for permeation rates based on concentration gradient, but this technology should be further explored in both static and loop tests, as the expressions are empirical and dependent on assumptions about tritium behavior that have not been rigorously tested. Permeation rates are likely to be low because of the low partial pressure of tritium in the primary loop. Application of an electric field to a proton-conducting membrane may effectively pump tritium from the loop. The engineering and testing of this material is very much in its infancy, especially in relation to FHR operation. It is recommended that fundamental research be conducted in this area to develop this concept for enhanced permeation rates.

\subsubsection{Task 2: Detailed Loop Design and Fabrication}

At the nominal operating temperature of the molten salt system, tritium and hydrogen permeation through the metal walls and structural components can be significant. In order to assess the effectiveness of a tritium removal or capture system, accounting for tritium losses throughout the balance of the test loop is important. Developing a method for tritium introduction that provides a bounded initial concentration of tritium can reduce uncertainties associated with the longer term system losses. To this end, features were incorporated into the flow loop design to reflect this proposed test methodology.

A process flow diagram is shown in Fig. 2 for the test loop. The storage tank in this concept provides a location for melting and freezing the salt but is not used for tritium or other component additions. The molten salt would be lifted into the test loop, and then a freeze valve on the vertical dip tube line would be cooled to isolate the storage tank from the remainder of the system. The molten salt has lower tritium/hydrogen permeability than the metal walls of the system, so the salt in the freeze valve should provide an adequate barrier.

The test loop consists of a cantilever-type centrifugal pump, an auxiliary/sample tank, and piping with flanged connections to allow installation of a test assembly. An example of a membrane-type test assembly is shown in the diagram where a bundle of thin-walled nickel tubes is installed in a U-shaped shell. Salt flows through the tubes, and the shell is swept with argon gas to collect tritium that has permeated through the tube walls. There are freeze valves and a bypass line upstream of the test assembly. The freeze valves allow isolation of the test assembly while flowing salt through the bypass line to establish initial tritium and redox conditions in the salt. Opening the freeze valves to the test assembly and closing the bypass freeze valve will initiate flow of salt to the test assembly.

An "addition tube" is shown entering the horizontal flow leg downstream of the bypass line. This is a potential method of injecting tritium/hydrogen into the flowing salt that depends on permeation of a nickel tube by the tritium or hydrogen, similar to the method used by Mays in the CSTF [2]. An alternative approach is the use of LiT pellets, as discussed in section 2.1. For this case, the pellets would likely be 
added to the auxiliary tank and dissolved in the salt. The small flow through the auxiliary tank would provide mixing into the main salt volume of the loop.

The auxiliary tank is designed to receive a small (leakage) flow from the pump and circulate salt back to the suction of the pump. Tritium can potentially be added in LiT form to establish initial conditions in the salt. The gas headspace in the auxiliary tank may be used for redox control of the salt via $\mathrm{H}_{2} / \mathrm{HF}$ addition.

An enclosure surrounds the pump, auxiliary tank, and piping up to the flanges where the test assembly is attached. This region is swept with argon gas and directed to the sampling system for measurement of the tritium content. This measurement represents tritium losses from the non-test assembly portion of the loop.

The storage tank will be fabricated from 8-inch Sch 10 pipe and end caps. A 6-inch Class 150 weld-neck flange will be welded to the tank body. The mating flange will contain ports for the dip tube and gas lines: a supply and vent for an argon cover gas used to inert the atmosphere in the tank and provide the gas pressure for moving salt into the test assembly. Metal C-ring seals are planned for the flange seals. These were chosen partly due to their capability for achieving low gas leak rates.

The storage tank will also be used as the transfer vessel for receiving salt from the salt purification system. The tank will be moved to the fume hood containing the salt purification system. A transfer tube will be connected between the purification vessel and the storage tank, and molten salt will be transferred between the tanks using dip tube(s) and gas pressure.

Gases will be supplied from cylinders with appropriate safety controls. The gas sources are shown in a simplified form in Fig. 2. Hazardous gas sources will include emergency shutoff valves (ESVs) at the cylinders to provide PLC (programmable logic controller) controlled shutoff under adverse conditions. This is shown for the HF source in Fig. 2, but not for the hydrogen and tritium gas supplies. Where possible, gas will be controlled using gas mass flow controllers. In some cases, it may be necessary to control gas addition to the system via partial pressure measurements in a known volume. Pressure transmitters with appropriate accuracy will be used in this case.

Tritium accounting will be an important factor in evaluating the effectiveness of tritium capture methods. The sampling system is not well defined at this point and should be considered only as a placeholder on the diagram. Additional detail and instrumentation will be added as the design progresses.

The system will be controlled by an Allen Bradley Controllogix PLC. The instrument cabinet with controller, input/output modules, and associated terminal strips has been completed as a joint effort with another project and is ready for field wiring connections in the lab. A photo of the instrument cabinet installed in the building 4505 lab is shown in Fig. 3. Process instrumentation will include pressure, flow, and temperature measurements.

A thermal management system will be made up of heater jackets and heat trace with heater power controlled by solid state relays through the PLC. The PLC heater control methodology was developed on a previous molten salt project and will be adapted for use on this system [28]. A temperature measurement for each heater zone is used as the input to a PID control loop that in turn controls the percentage of time that the heater is turned on via the solid state relays.

Several of the loop components will require development. A pump with a suitable flow rate and developed head must be procured. In particular, a pump with dry gas seals is desirable to eliminate potential reaction with organic-based lubricants that are more commonly used in lubricated bearings and seals in high temperature pumps. The FLiNaK test loop at ORNL [28] has successfully used dry gas seals, although 
operating hours on the seals are not extensive at this time. Key elements of the pump specification are shown in Table 5.

Table 5. Pump specification notes

\begin{tabular}{ll}
\hline Parameter & Note \\
\hline Flow rate & $1 \mathrm{~L} / \mathrm{s}(16 \mathrm{gpm})$ \\
Total developed head (TDH) & $148 \mathrm{kPa}(25$ feet of salt) \\
Pump style & Cantilever shaft design with dry gas seals located outside \\
of wetted salt and high temperature zone \\
Fluid temperature & $700^{\circ} \mathrm{C}$ (normal operating) \\
Wetted material & Hastelloy C276 \\
\hline
\end{tabular}

The analysis used to develop pump head requirements is described below (Sec. 4.1). The shaft length for the pump and the location of seals and bearings are also important, especially considering the space limitations imposed by the walk-in hood. A sketch showing the pump installed above the storage tank is shown in Fig. 4. There is approximately $1.25 \mathrm{~m}$ available from the bottom of the pump to the top of the inside of the walk-in hood for the pump seals, bearings, and motor. An alternate design shown would extend the shaft and locate the motor above the hood top, with the dry gas seal located further from the high temperature region but still inside the hood.

The salt level in the pump (and auxiliary tank) will be the highest fluid level in the system. An argon gas cover with trace amounts of $\mathrm{H}_{2} / \mathrm{HF}$ will be maintained above the salt level in the pump casing and auxiliary tank, also enabling the use of the dry gas seals on the pump shaft. A designed leakage flow rate through the pump or a small percentage bypass flow to the auxiliary tank will be used to provide a well-mixed representation of the molten salt condition in the flowing salt.

Freeze valves have been used in other molten salt applications at ORNL but the specific size and geometry will be new. Some development and testing of the freeze valves will be included in the scope of the project.

Methods for redox potential measurement and control must be developed for the test loop. Sensor development is part of the Phase 1 work scope, as described previously (Sec. 3.1.3). 


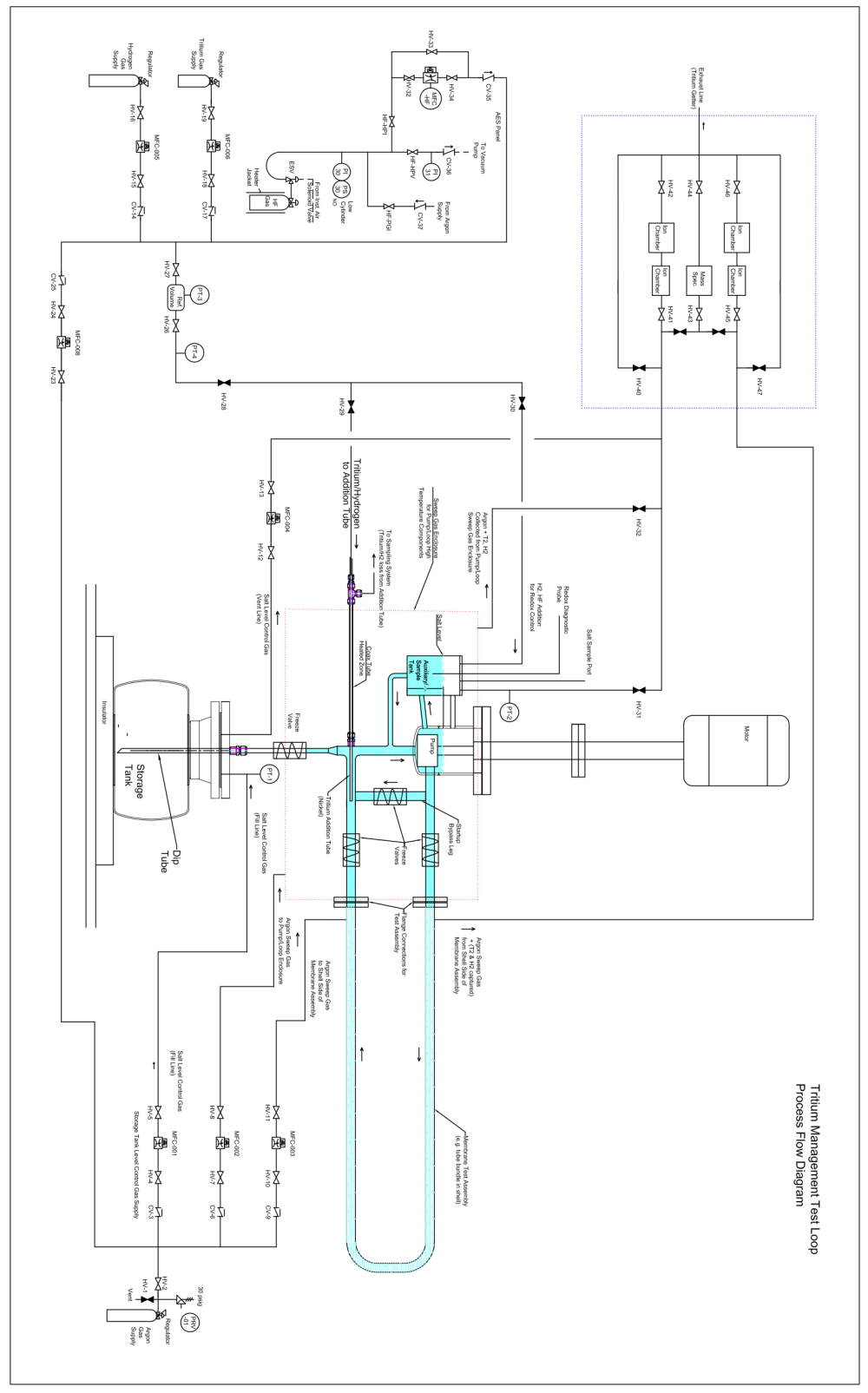

Figure 2. Process flow diagram for the test loop. 


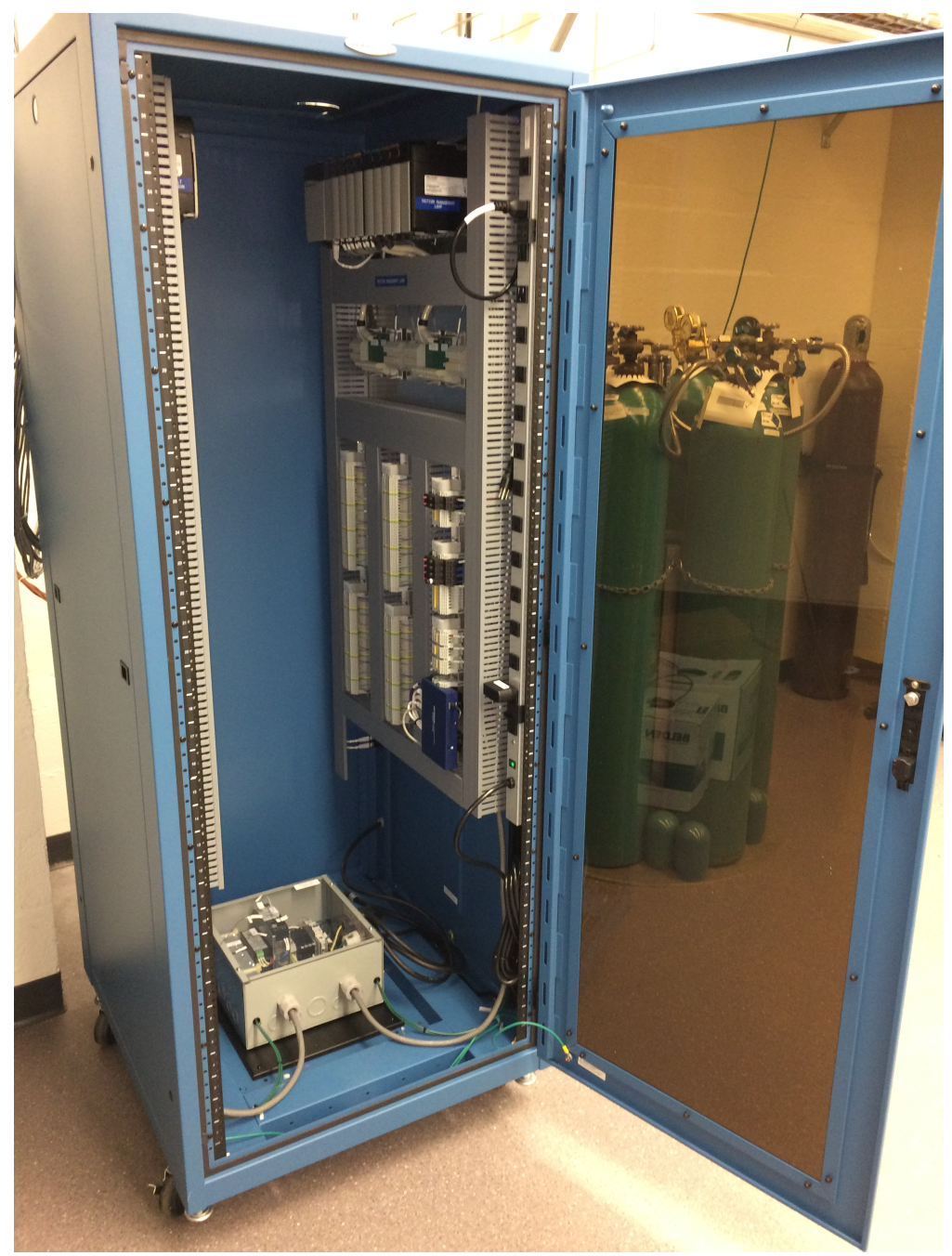

Figure 3. Instrument cabinet. 


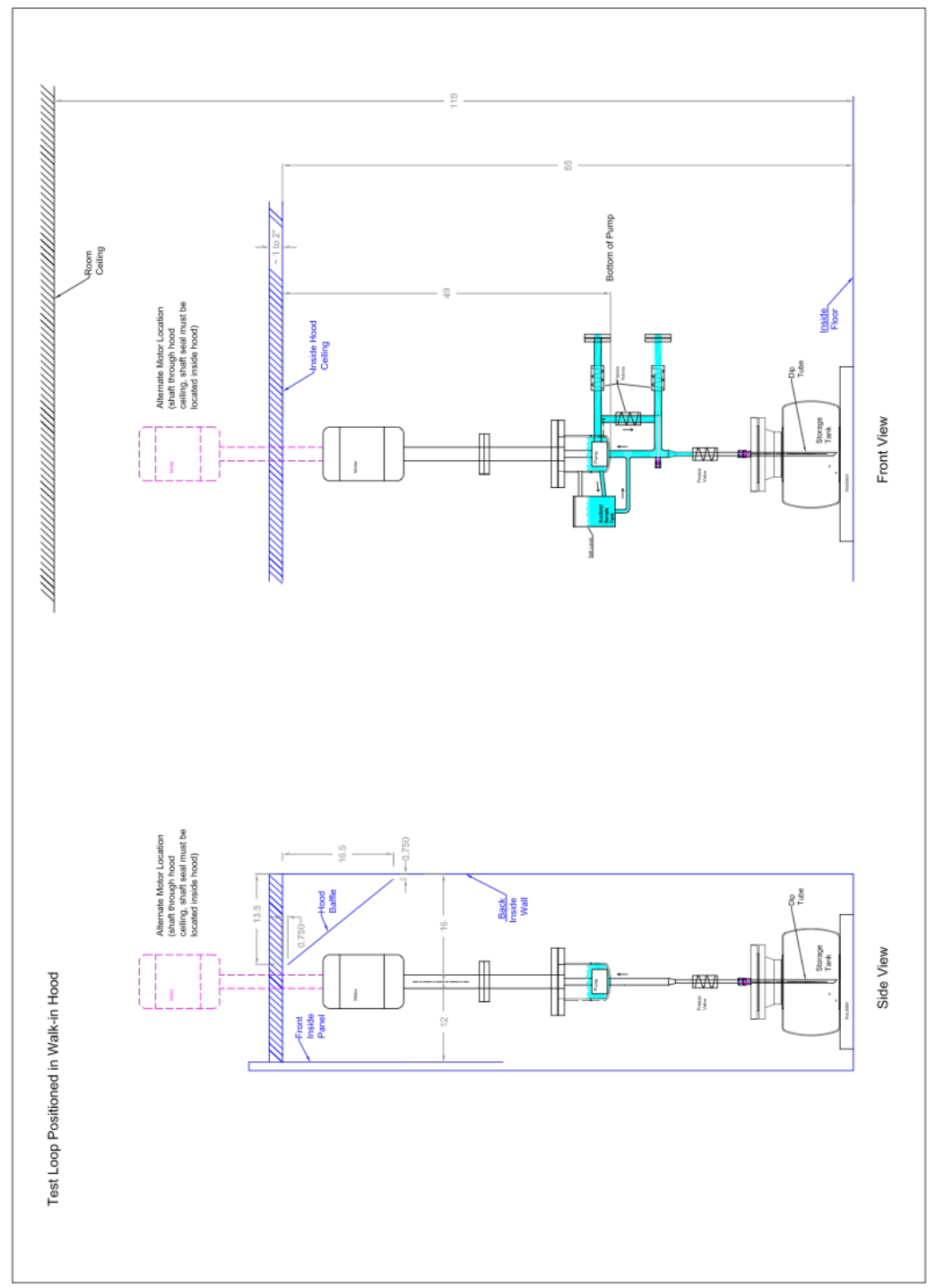

Figure 4. Test loop positioned in walk-in hood showing relative dimensions to hood boundaries. 



\section{DESIGN CALCULATIONS}

\subsection{Loop Pressure Drop Scoping Evaluation}

The pump for this loop must accommodate planned and unplanned loop design changes. A pressure drop calculation was performed in Mathcad [29] using the design shown in Fig. 2. The Mathcad workbook acts as a design tool, easily allowing the user to change pipe and tube geometry, as well as salt temperature and flowrate. Additional hydraulic components can be added as required. A snapshot of the schematic is provided in Fig. 5.

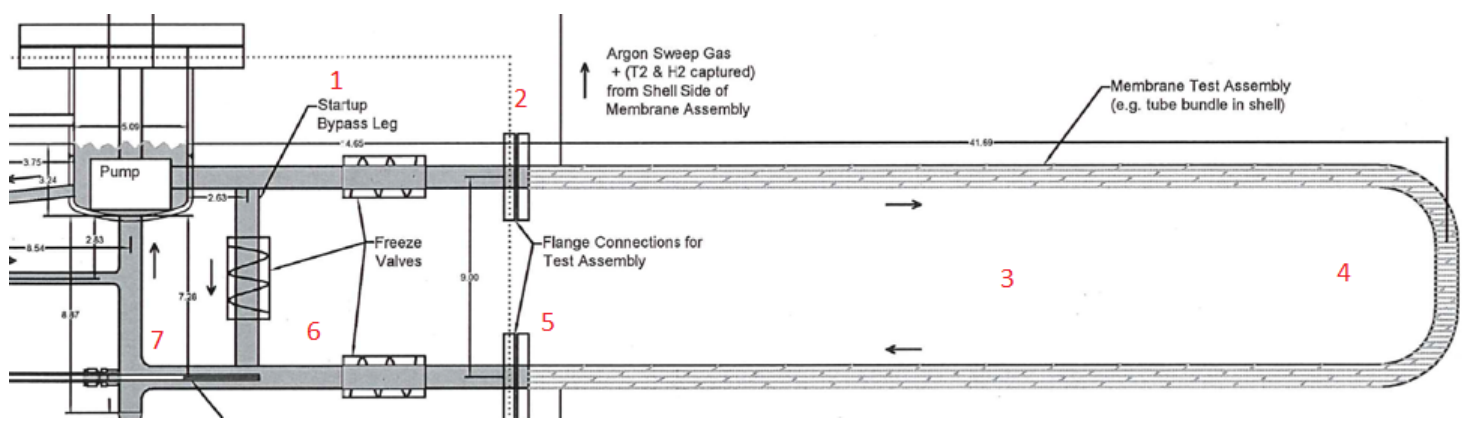

Figure 5. Flow loop schematic excerpt showing permeator test section and pump. Sections of loop numbered for convenience.

A model of the molten salt loop in RELAP5-3D 4.3.4 [30] was created using the SNAP tool [31] to benchmark the capability of RELAP5-3D to help with future loop analysis. A breakout of the pressure drops of the components of the molten salt loop for both the Mathcad and RELAP5-3D calculations for an example statepoint is provided in Table 6. As shown in the table, there is good agreement between the RELAP5-3D calculation and the Mathcad calculation at each individual component.

Table 6. Pressure losses in molten salt flow loop at $1.9 \mathrm{~L} / \mathrm{s}(30 \mathrm{gpm})$ and $700^{\circ} \mathrm{C}$

\begin{tabular}{lcclc}
\hline Loss Type & $\begin{array}{c}\text { Mathcad } \\
{[\mathbf{k P a}]}\end{array}$ & $\begin{array}{c}\text { RELAP5-3D } \\
{[\mathbf{k P a}]}\end{array}$ & Description & $\begin{array}{c}\text { No. in } \\
\text { Fig. 5 }\end{array}$ \\
\hline Friction & 8.9 & 8.9 & Flow in pump outlet line & 1 \\
Form & 11.8 & 11.8 & Area change into permeator & 2 \\
Friction & 130.6 & 130.8 & Flow in permeator tubes & 3 \\
Form & 30.1 & 30.2 & Bends in permeator tubes & 4 \\
Form & 17.4 & 17.4 & Area change from permeator & 5 \\
Friction & 15.9 & 15.5 & Flow in pump inlet line & 6 \\
Form & 15.8 & 15.9 & Bend in pump inlet line & 7 \\
\hline Total & $\mathbf{2 3 0 . 5}$ & $\mathbf{2 3 0 . 5}$ & & \\
\hline
\end{tabular}

A comparison of the pressure drop as a function of flowrate at the design temperature is shown in Fig. 6. The two curves show excellent agreement at all flowrates and are nearly indistinguishable.

The pressure drop at $1.9 \mathrm{~L} / \mathrm{s}(30 \mathrm{gpm})$ is somewhat higher than desired from a system operating pressure perspective (Table 5). At half the flow rate, $0.95 \mathrm{~L} / \mathrm{s}(15 \mathrm{gpm})$, the total pressure drop is reduced to $67 \mathrm{kPa}$. The Reynolds number in the permeator tubes for this lower flow is $\sim 6700$, as compared to $\sim 13500$ for the 


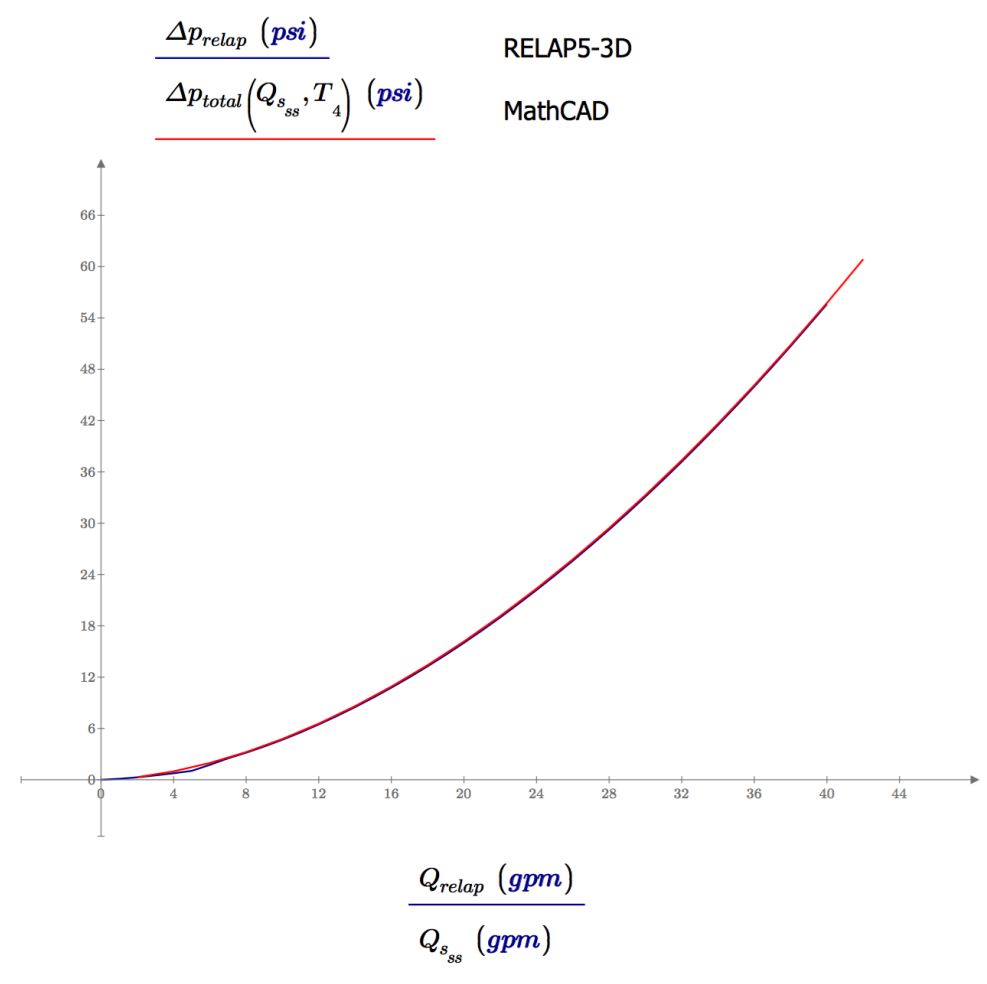

Figure 6. Comparison between RELAP5-3D and Mathcad of the total loop pressure drop as a function of flowrate at $700^{\circ} \mathrm{C}$.

higher flow case, both in the turbulent flow regime. The breakdown of pressure drop data is shown in Table 7 for the lower flow rate.

Table 7. Pressure losses in molten salt flow loop at $0.95 \mathrm{~L} / \mathrm{s}(15 \mathrm{gpm})$ and $700^{\circ} \mathrm{C}$

\begin{tabular}{lcclc}
\hline Loss Type & $\begin{array}{c}\text { Mathcad } \\
{[\mathbf{k P a}]}\end{array}$ & $\begin{array}{c}\text { RELAP5-3D } \\
{[\mathbf{k P a}]}\end{array}$ & Description & $\begin{array}{c}\text { No. in } \\
\text { Fig. 5 }\end{array}$ \\
\hline Friction & 2.6 & 2.6 & Flow in pump outlet line & 1 \\
Form & 3.0 & 3.0 & Area change into permeator & 2 \\
Friction & 39.1 & 39.2 & Flow in permeator tubes & 3 \\
Form & 9.0 & 9.1 & Bends in permeator tubes & 4 \\
Form & 4.3 & 4.4 & Area change from permeator & 5 \\
Friction & 4.4 & 4.6 & Flow in pump inlet line & 6 \\
Form & 4.7 & 4.7 & Bend in pump inlet line & 7 \\
\hline Total & $\mathbf{6 7 . 1}$ & $\mathbf{6 7 . 1}$ & & \\
\hline
\end{tabular}

Finally, the loop pressure drop as a function of flowrate was also calculated at design and limiting temperatures using Mathcad, as shown in Fig. 7. As the FLiBe salt has a higher viscosity at low temperature, the pressure drop is much higher than when it was at the elevated design temperature. This is an important consideration when designing the loop, as it will be useful to perform tests at different temperatures. It is recognized that $500^{\circ} \mathrm{C}$ may be conservatively low. The point of the figure is to emphasize the need to consider a range of operating temperatures when sizing components and designing the loop. 


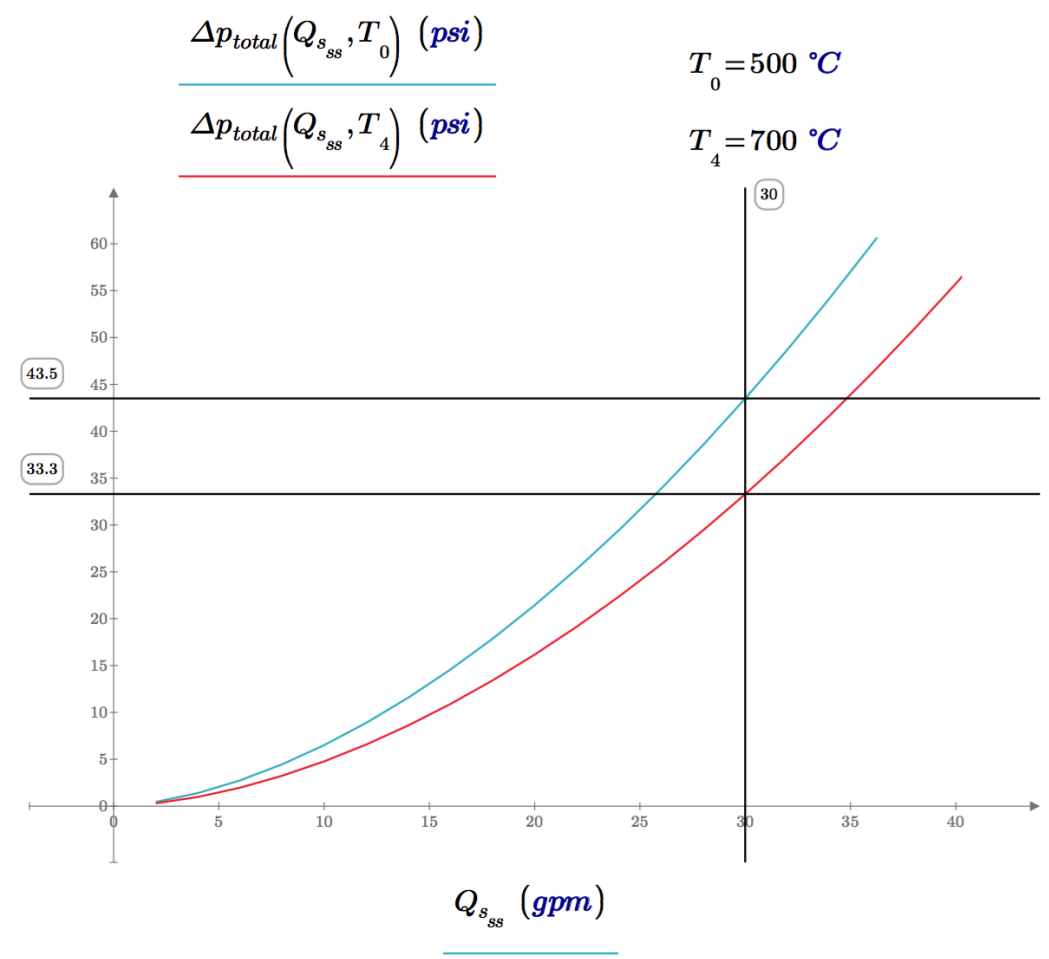

Figure 7. Comparison of loop pressure drop as a function of flowrate at two temperatures using Mathcad. 


\subsection{Tritium Transport Modeling}

A generic trace substance transport model has been developed in the Modelica environment [32] in the latest version of the ORNL TRANSFORM Library. This model allows for dynamic solubility modeling of trace substances according to both Henry's and Sievert's laws. It also allows for transport of trace substances between fluid and solid materials. The transport model is directly coupled to the thermal-hydraulic solution and draws the temperature and flow field from the heat transfer and fluid flow solution. Diffusion, solubility, and permeability of trace substances in fluids and solids is calculated dynamically allowing for analysis of transients.

Multiple trace substances can be tracked. Each trace substance interacts with materials independent of other trace substances. Trace substances can also interact with each other simulating chemical reactions. Together, these models allow for calculation of tritium transport and speciation in a molten salt loop. Additional capabilities not used in this analysis include (1) radioactive decay models for each trace substance with allowance for one trace substance decaying into another, (2) fission source of trace substance which can be coupled to a power source/distribution, and (3) transmutation of trace substance from exposure to radiation. While each of these capabilities is interesting to consider and provides the user with power to model many scenarios, the focus here is on tritium transport and speciation.

Discussion of tritium transport modeling begins with model comparisons to analytical results (Sec. 4.2.1) and is followed by modeling of the proposed test loop (Sec. 4.3).

\subsubsection{Model Comparison with Analytical Results}

Two comparisons to analytical results are now described. The first is for tritium in $\mathrm{Pb}-17 \mathrm{Li}$ as described in Humrickhouse and Merrill [33]. The second is for a molten salt application.

\subsubsection{Sievert's Law Application}

The Modelica model of the vacuum permeator described in Humrickhouse and Merrill [33] is shown in Fig. 8.

The model is straightforward. A constant mass source of $\mathrm{Pb}-17 \mathrm{Li}$ at a fixed temperature is given a known concentration of tritium. The $\mathrm{Pb}-17 \mathrm{Li}$ flows through the permeator, depositing its tritium in reduced activation ferritic martensitic (RAFM) tubes. Since tritium is dissolved in $\mathrm{Pb}-17 \mathrm{Li}$ and RAFM according to Sievert's law, the interface condition between the fluid and the metal is given by (14):

$$
\frac{C_{\mathrm{PbLi}}}{K_{\mathrm{PbLi}}}=\frac{C_{\mathrm{RAFM}}}{K_{\mathrm{RAFM}}}
$$

The vacuum condition on the outside of the tubes acts as a tritium sink. The ratio of the amount of tritium that exits the permeator dissolved in the fluid is compared to the amount that entered, resulting in a calculation of the removal efficiency, $\eta$. The efficiency as a function of time as calculated by Modelica is shown in Fig. 9. 


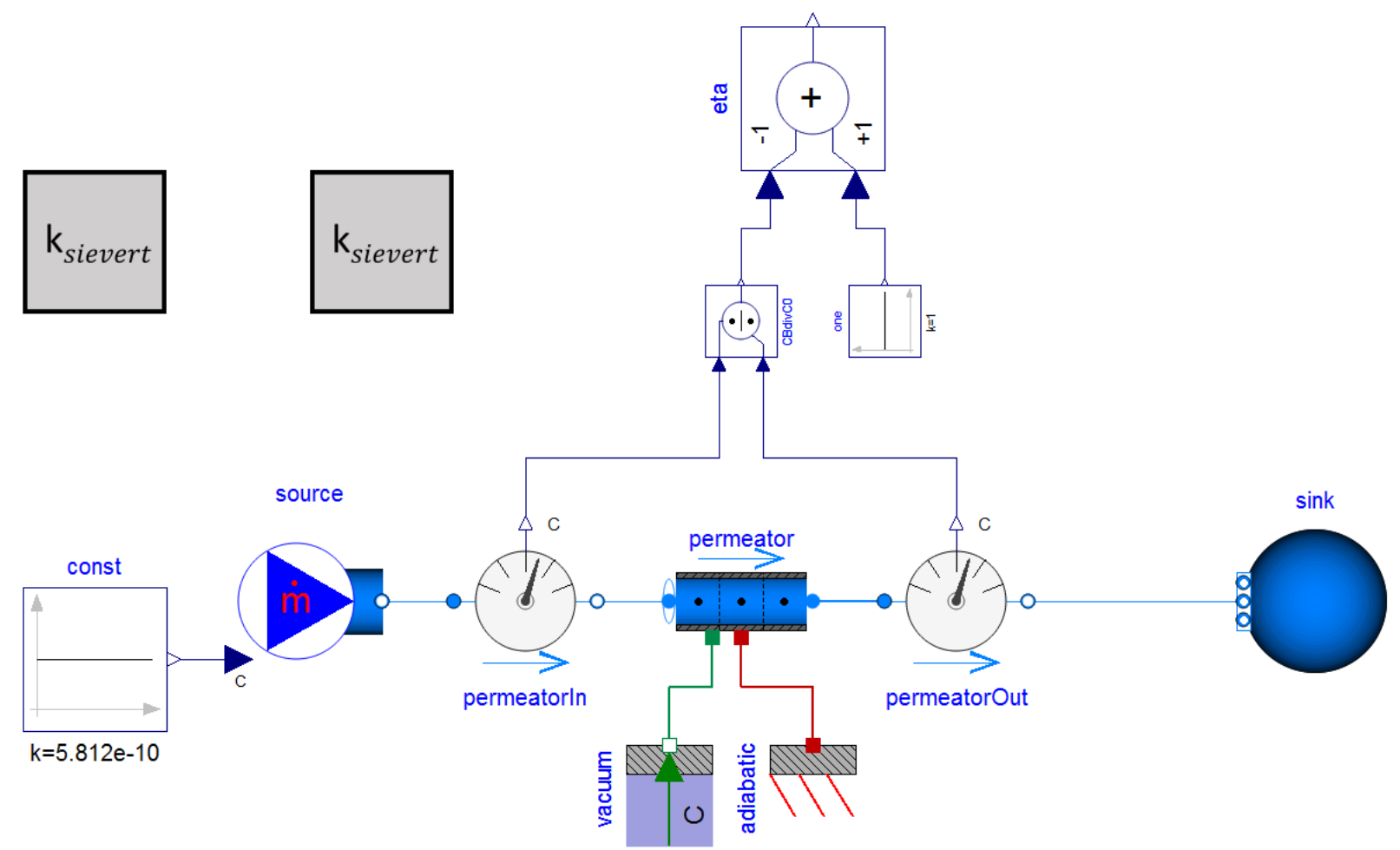

Figure 8. Modelica model for PbLi vacuum permeator test.

The fina, steady-state value matches well with that calculated using the methodology adapted from Humrickhouse and Merrill [33] as listed in Table 8. The exact values from [33] are not used, but instead they were recalculated to match the Sherwood number correlation used in Modelica. Namely, the exponent on the Schmidt number is $2 / 5$ in Modelica and $1 / 3$ in [33]. The tritium concentration as a function of axial position in the permeator at different radial locations is shown in Fig. 10 for new and original models.

Excellent agreement is demonstrated. The concentration of tritium at the beginning, middle, and end of the permeator as a function of radial position for both the new and original work is listed in Table 8. A summary of key parameters from the original work and the present work is given in Table 9. 


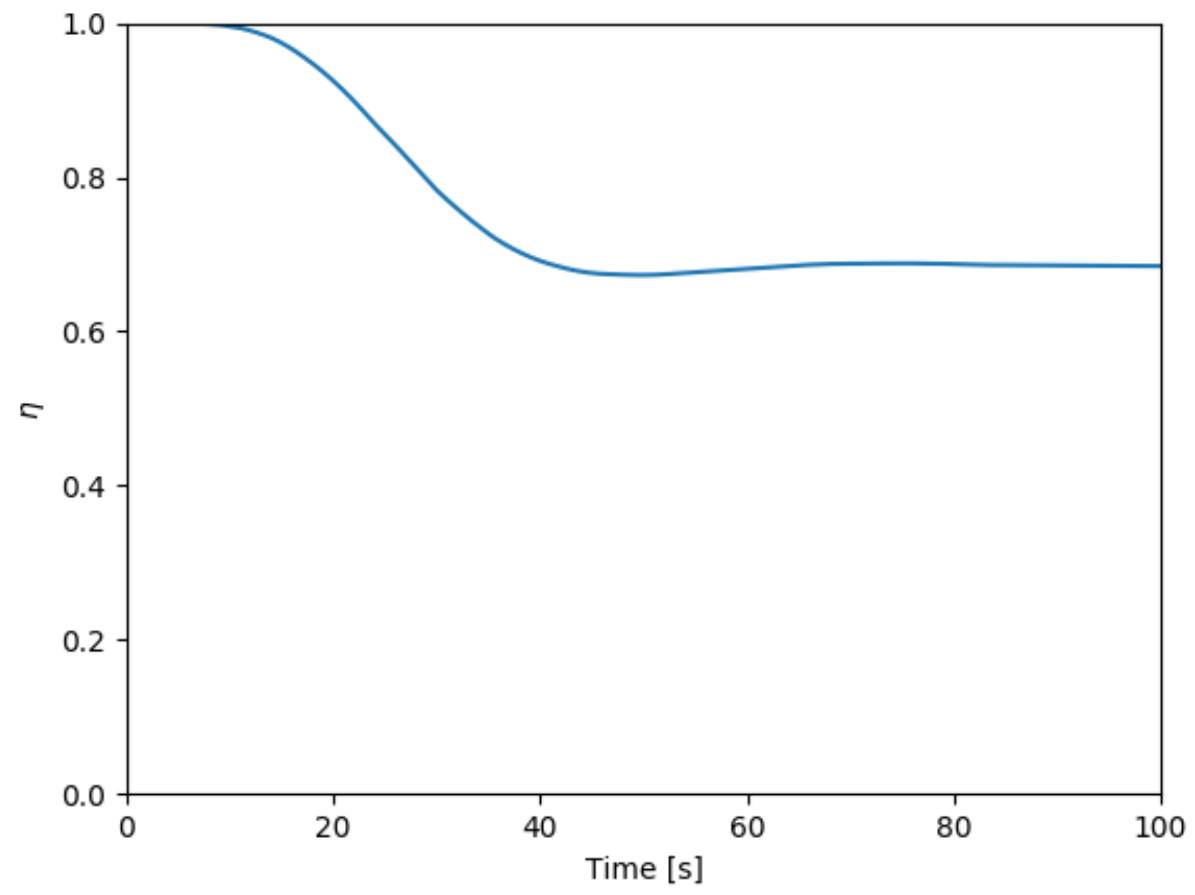

Figure 9. Time history of $\mathrm{Pb}-17 \mathrm{Li}$ vacuum permeator tritium removal efficiency.

Table 8. Radial tritium distribution for $\mathrm{Pb}-17 \mathrm{Li}$ comparison

\begin{tabular}{|c|c|c|c|c|}
\hline Loc. & Rad. Pos. & $\begin{array}{l}\text { Theo. Val. } \\
\text { [frac. inlet] }\end{array}$ & $\begin{array}{l}\text { Calc. Val. } \\
\text { [frac. inlet] }\end{array}$ & Comment \\
\hline \multirow{3}{*}{ Inlet } & Bulk & 0.984 & 0.969 & \multirow{3}{*}{$\begin{array}{l}\text { Middle of first } \\
\text { permeator volume }\end{array}$} \\
\hline & Liq. Int. & 0.655 & 0.645 & \\
\hline & Sol. Int. & 5.508 & 5.420 & \\
\hline \multirow{3}{*}{ Middle } & Bulk & 0.557 & 0.553 & \multirow{3}{*}{$\begin{array}{l}\text { Middle of center } \\
\text { permeator volume }\end{array}$} \\
\hline & Liq. Int. & 0.371 & 0.368 & \\
\hline & Sol. Int. & 3.117 & 3.096 & \\
\hline \multirow{3}{*}{ Outlet } & Bulk & 0.315 & 0.316 & \multirow{3}{*}{$\begin{array}{l}\text { Middle of last } \\
\text { permeator volume }\end{array}$} \\
\hline & Liq. Int. & 0.210 & 0.209 & \\
\hline & Sol. Int. & 1.764 & 1.760 & \\
\hline
\end{tabular}

Table 9. Comparison of $\mathrm{PbLi}$ analytical results to present model

\begin{tabular}{lcccc}
\hline Parameter & Symbol & Theo. Val. & Calc. Val. & Units \\
\hline Removal efficiency & $\eta$ & 0.690 & 0.684 & - \\
Mass transfer coefficient & $K_{T}$ & 0.414 & 0.414 & $\mathrm{~mm} / \mathrm{s}$ \\
\hline
\end{tabular}




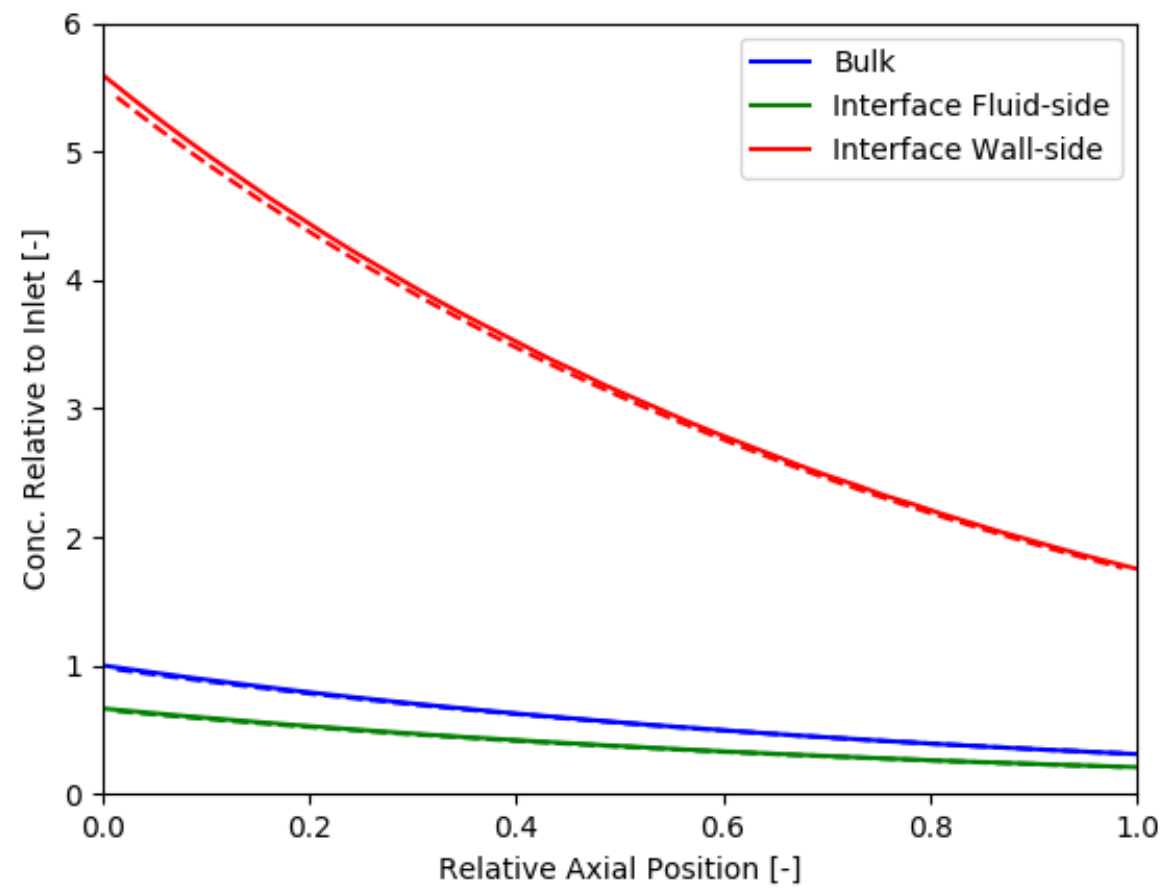

Figure 10. Axial tritium distribution at three radial locations for PbLi permeator test. Theoretical values solid and Modelica values dashed. 


\subsubsection{Henry's Law Application}

Similar to the above calculation, an ideal vacuum permeator is created in Modelica using FLiBe as the carrier salt and nickel as the tube material. The Modelica model is shown in Fig. 11.

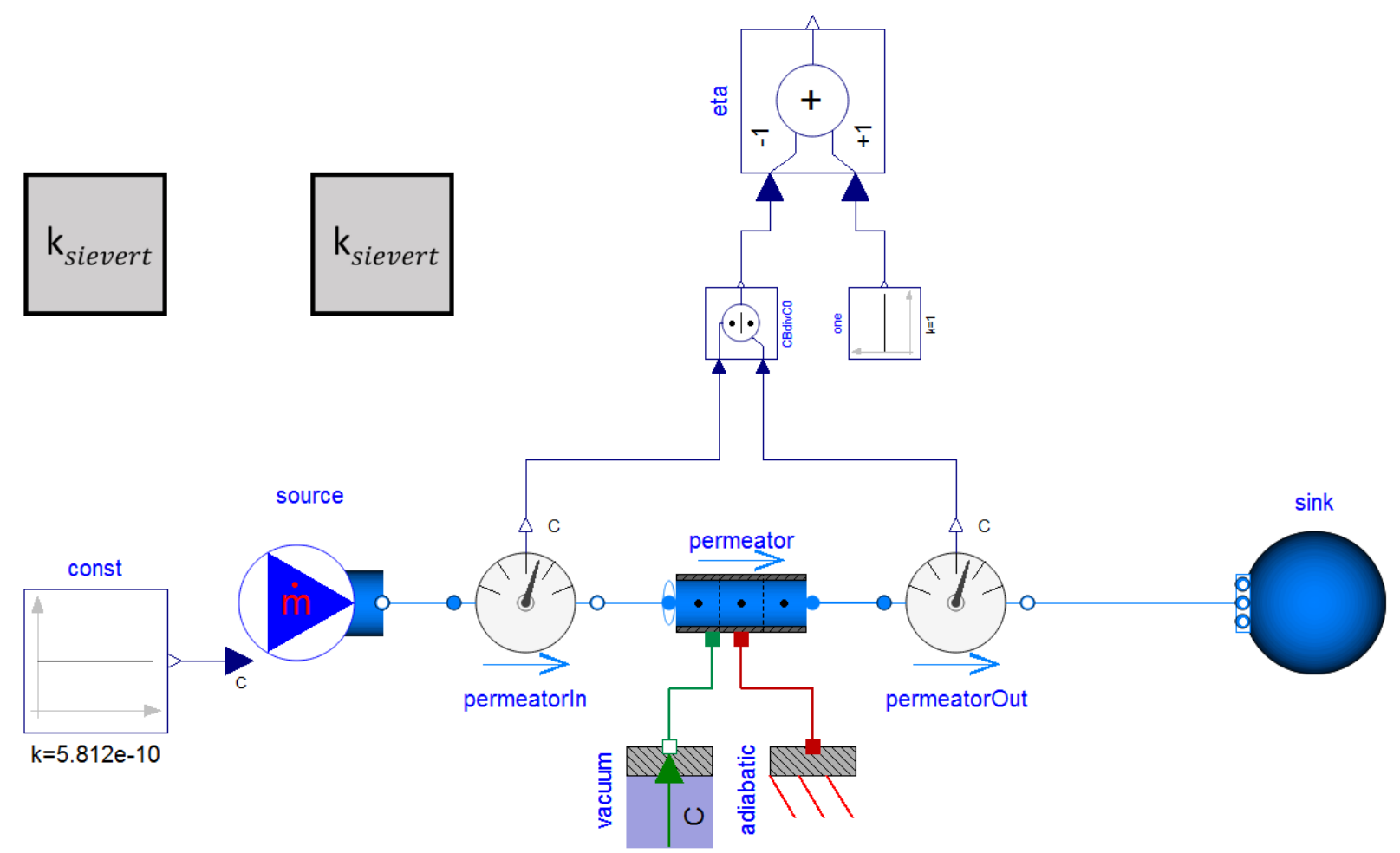

Figure 11. Modelica model for FLiBe vacuum permeator test.

Since tritium is soluble according to Henry's law in FLiBe and Sievert's law in nickel, the interface condition between the salt and the metal is changed as shown in Eq. (15):

$$
\frac{C_{\mathrm{FLiBe}}}{K_{\mathrm{FLiBe}}}=\left(\frac{C_{\mathrm{Ni}}}{K_{\mathrm{Ni}}}\right)^{2}
$$

As there is no reference document, key parameters for this test are listed in Table 10. Correlations are listed in Table 11. The derivation of the analytical solution is provided in App. B.

Table 10. Parameters for FLiBe test

\begin{tabular}{lccc}
\hline Parameter & Symbol & Value & Units \\
\hline Length & $L$ & 50 & $\mathrm{~m}$ \\
Inner diameter & $d$ & 2.54 & $\mathrm{~cm}$ \\
Outer diameter & $d_{o}$ & 2.59 & $\mathrm{~cm}$ \\
Velocity & $v$ & 2.5 & $\mathrm{~m} / \mathrm{s}$ \\
Temperature & $T$ & 700 & ${ }^{\circ} \mathrm{C}$ \\
\hline
\end{tabular}


Table 11. Correlations for FLiBe test (Temperatures in K)

\begin{tabular}{lccc}
\hline Parameter & Symbol & Value & Units \\
\hline FLiBe Density & $\rho$ & $2415.6-0.49072 T$ & $\mathrm{~kg} / \mathrm{m}^{3}$ \\
FLiBe Viscosity & $\mu$ & $1.16 \times 10^{-4} \exp \left(\frac{3755}{T}\right)$ & $\mathrm{Pa}-\mathrm{s}$ \\
Sherwood Number & $\mathrm{Sh}$ & $0.023 \mathrm{Re}^{4 / 5} \mathrm{Sc}^{2 / 5}$ & - \\
Diffusion coefficient $\left(\mathrm{T}_{2}\right.$ in FLiBe$)$ & $D_{l}$ & $9.3 \times 10^{-7} \exp \left(\frac{-42000}{R T}\right)$ & $\mathrm{m}^{2} / \mathrm{s}$ \\
Henry's law constant $\left(\mathrm{T}_{2}\right.$ in FLiBe $)$ & $K_{H}$ & $8.27 \times 10^{-9} \exp \left(4.27 \times 10^{-3} T\right)$ & $\mathrm{mol} / \mathrm{m}^{3}-\mathrm{Pa}$ \\
Diffusion coefficient $\left(\mathrm{T}_{2}\right.$ in $\left.\mathrm{Ni}\right)$ & $D_{s}$ & $7.43 \times 10^{-7} \exp \left(\frac{-44100}{R T}\right)$ & $\mathrm{m}^{2} / \mathrm{s}$ \\
Solubility $\left(\mathrm{T}_{2}\right.$ in $\left.\mathrm{Ni}\right)$ & $K_{s}$ & $953 \times \exp \left(\frac{-10700}{R T}\right)$ & $\mathrm{mol} / \mathrm{m}^{3}-\sqrt{\mathrm{MPa}}$ \\
\hline
\end{tabular}

An efficiency, $\eta$, is calculated as a function of time using the Modelica model, as shown in Fig. 12. Steady-state axial distributions at fixed radial locations for both the theoretical and Modelica models are shown in Fig. 13. Radial tritium distributions at fixed axial locations are given in Table 12, with key calculated values summarized in Table 13. Excellent agreement is demonstrated.

Now that the trace substance model has been compared to both Sievert's and Henry's analytical solutions, the model for scoping out the performance of the test loop can be used with confidence.

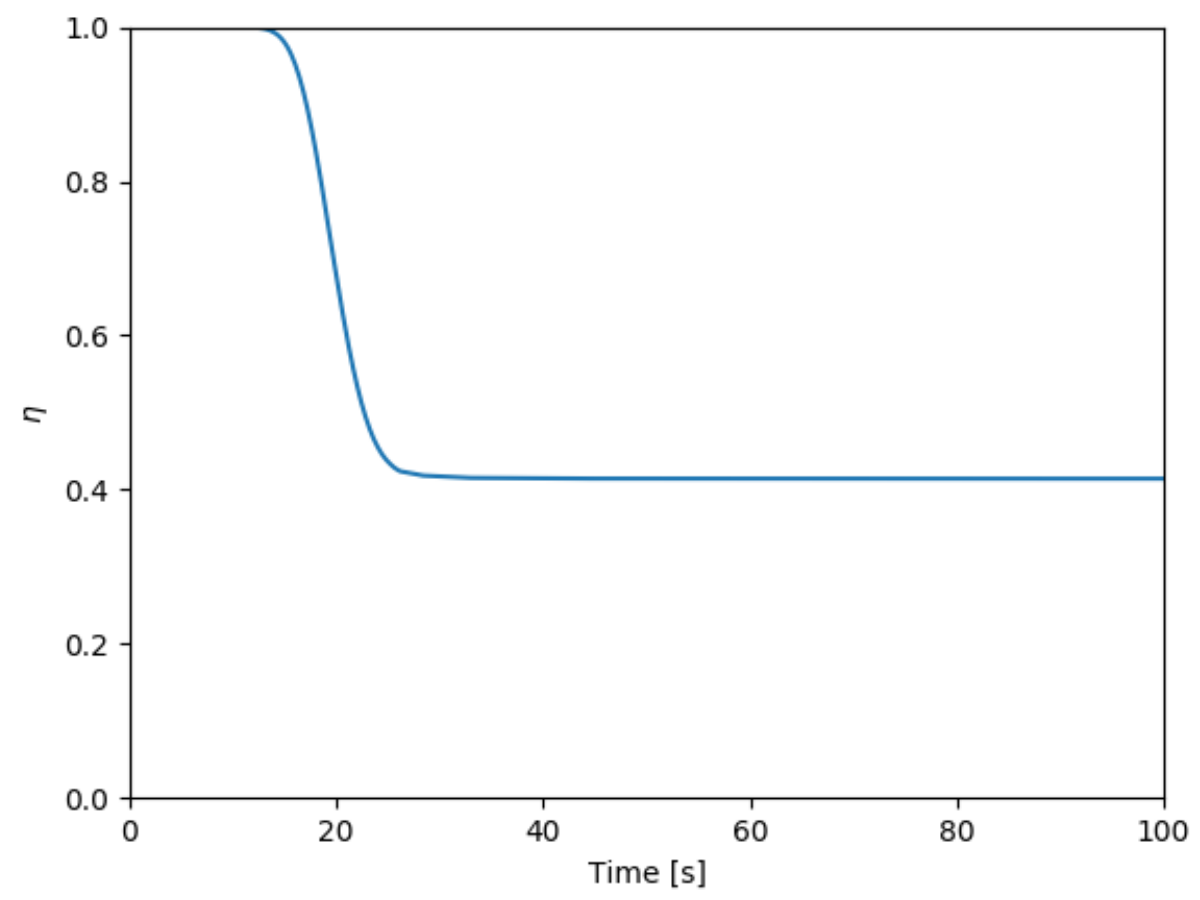

Figure 12. Time history of FLiBe vacuum permeator tritium removal efficiency. 


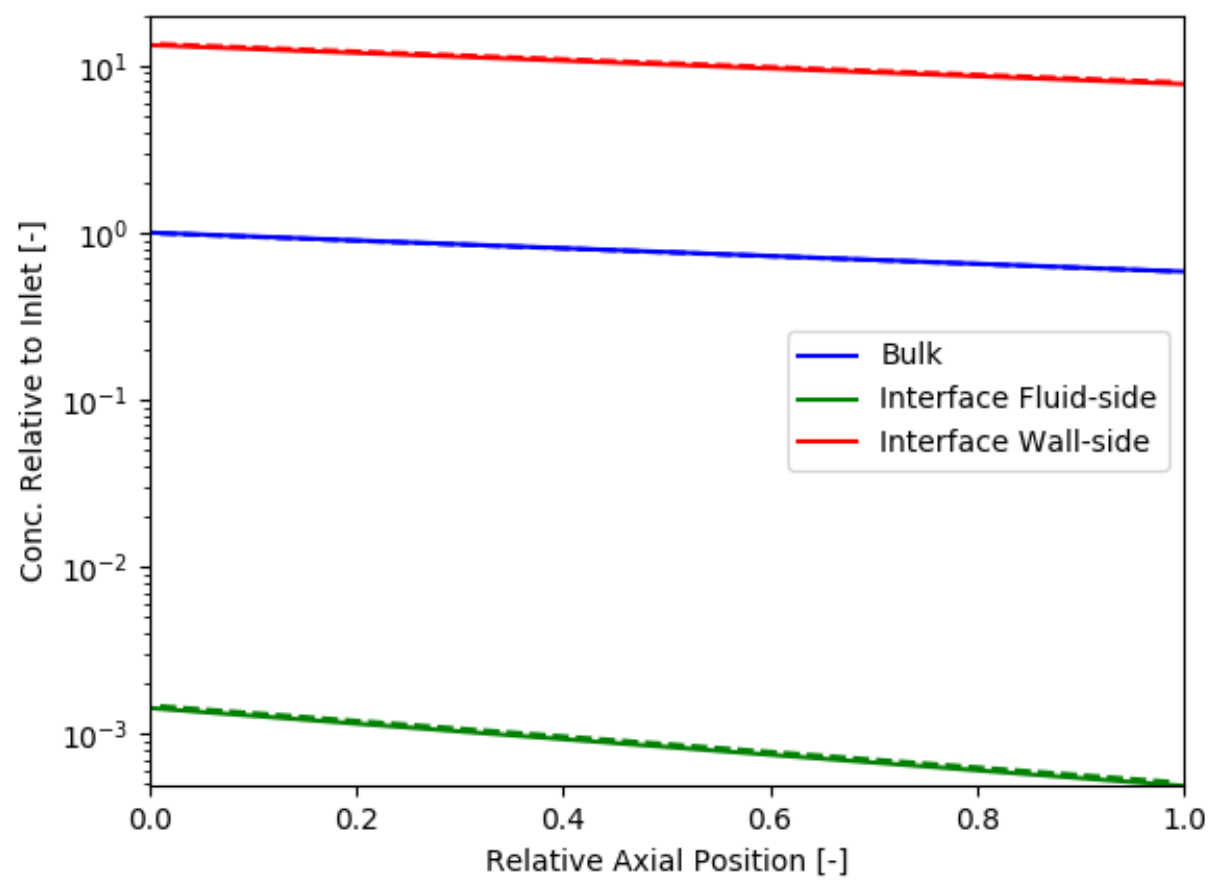

Figure 13. Axial tritium distribution at three radial locations for FLiBe permeator test. Theoretical values solid and Modelica values dashed.

Table 12. Radial tritium distribution for FLiBe comparison

\begin{tabular}{|c|c|c|c|c|}
\hline Loc. & Rad. Pos. & $\begin{array}{l}\text { Theo. Val. } \\
\text { [frac. inlet] }\end{array}$ & $\begin{array}{l}\text { Calc. Val. } \\
\text { [frac. inlet] }\end{array}$ & Comment \\
\hline \multirow{3}{*}{ Inlet } & Bulk & 0.995 & 0.989 & \multirow{3}{*}{$\begin{array}{l}\text { Middle of first } \\
\text { permeator volume }\end{array}$} \\
\hline & Liq. Int. & $1.415 \times 10^{-3}$ & $1.468 \times 10^{-3}$ & \\
\hline & Sol. Int. & 13.157 & 13.420 & \\
\hline \multirow{3}{*}{ Middle } & Bulk & 0.765 & 0.762 & \multirow{3}{*}{$\begin{array}{l}\text { Middle of center } \\
\text { permeator volume }\end{array}$} \\
\hline & Liq. Int. & $8.369 \times 10^{-4}$ & $8.707 \times 10^{-4}$ & \\
\hline & Sol. Int. & 10.118 & 10.334 & \\
\hline \multirow{3}{*}{ Outlet } & Bulk & 0.588 & 0.586 & \multirow{3}{*}{$\begin{array}{l}\text { Middle of last } \\
\text { permeator volume }\end{array}$} \\
\hline & Liq. Int. & $4.948 \times 10^{-4}$ & $5.161 \times 10^{-4}$ & \\
\hline & Sol. Int. & 7.780 & 7.956 & \\
\hline
\end{tabular}

Table 13. Comparison of FLiBe analytical results to present model

\begin{tabular}{lcccc}
\hline Parameter & Symbol & Theo. Val. & Calc. Val. & Units \\
\hline Removal efficiency & $\eta$ & 0.415 & 0.414 & - \\
Reynolds number & $\mathrm{Re}$ & 20616 & 20619 & - \\
Schmidt number & $\mathrm{Sc}$ & 595 & 595 & - \\
Sherwood number & $\mathrm{Sh}$ & 838 & 837 & - \\
Mass transfer coefficient & $K_{T}$ & 0.171 & 0.171 & $\mathrm{~mm} / \mathrm{s}$ \\
\hline
\end{tabular}




\subsection{Modeling of Test Loop}

A Modelica model of the test loop has been created, as shown in Fig. 14. The model contains all of the relevant components shown in Fig. 5 and also includes the sweep gas system. As a vacuum condition outside the permeator is no longer appropriate, a binary gas mass diffusion coefficient is calculated for tritium in Ar as described in App. A. This model is capable of modeling simultaneous transport of $\mathrm{T}_{2}$ and TF, but the redox control capability is not yet implemented. Therefore, results are not presented and are reserved for a future publication, where a more thorough investigation of the predicted test loop performance can be provided.

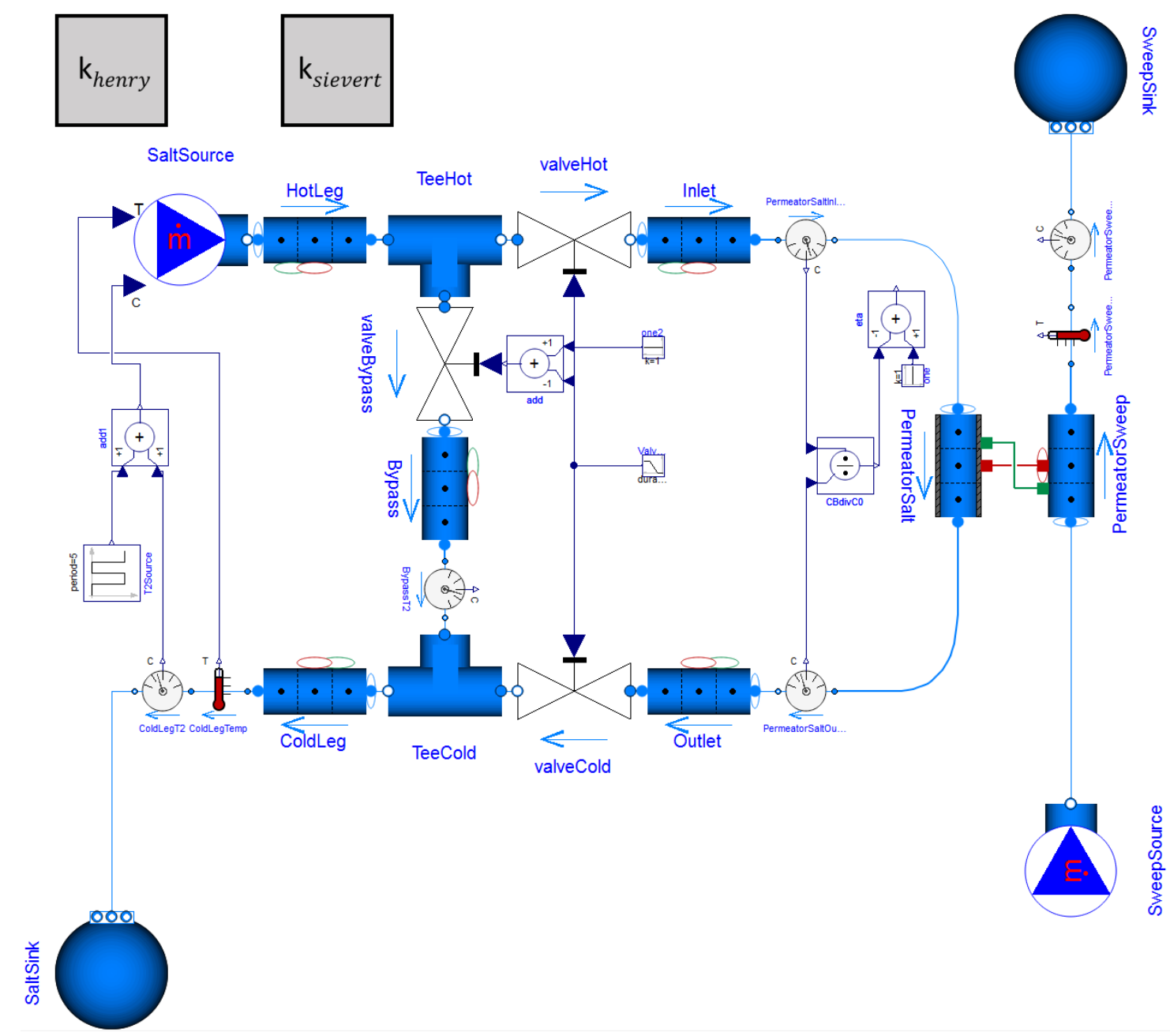

Figure 14. Modelica model for test loop.

\subsection{Planned Analysis}

The Modelica model of the test loop from Sec. 4.3 can also be used to perform the pressure drop calculations replacing the model shown in Sec. 4.1. Further, the tritium transport modeling capabilities can be expanded to simultaneously consider $\mathrm{T}_{2}$ and $\mathrm{TF}$ with redox control. Currently, both $\mathrm{T}_{2}$ and $\mathrm{TF}$ can 
simultaneously be a trace substance, but their interaction is not easily accommodated in the current version of TRANSFORM. A simple first step would be to force a ratio of $\mathrm{T}_{2}$ to $\mathrm{TF}$, as presented in Sec. 2.2, over a range of fixed redox potentials. Later, the model could be modified to explicitly include the cover gas behavior, as well as $\mathrm{H} / \mathrm{T}$ isotopic exchange and $\mathrm{H}_{2}$ or $\mathrm{HT}$ and $\mathrm{HF}$ transport.

A useful validation activity for the tritium transport modeling is to compare the model to experimental data from the CSTF [2]. Several steady-state and transient experiments were performed which could be used to benchmark the model while waiting for the construction of the loop and procurement of loop materials. 


\section{COST AND SCHEDULE}

Cost for the development program has been estimated assuming a 6-year timeline at $\sim \$ 7.3 \mathrm{M}$. Major tasks are shown in Fig. 15. System checkout is shown covering two years and reflects the addition of tritium instrumentation and other components that are phased in the schedule to spread out some of the hardware acquisition costs. Cost breakdown by year is shown at the bottom of the schedule.

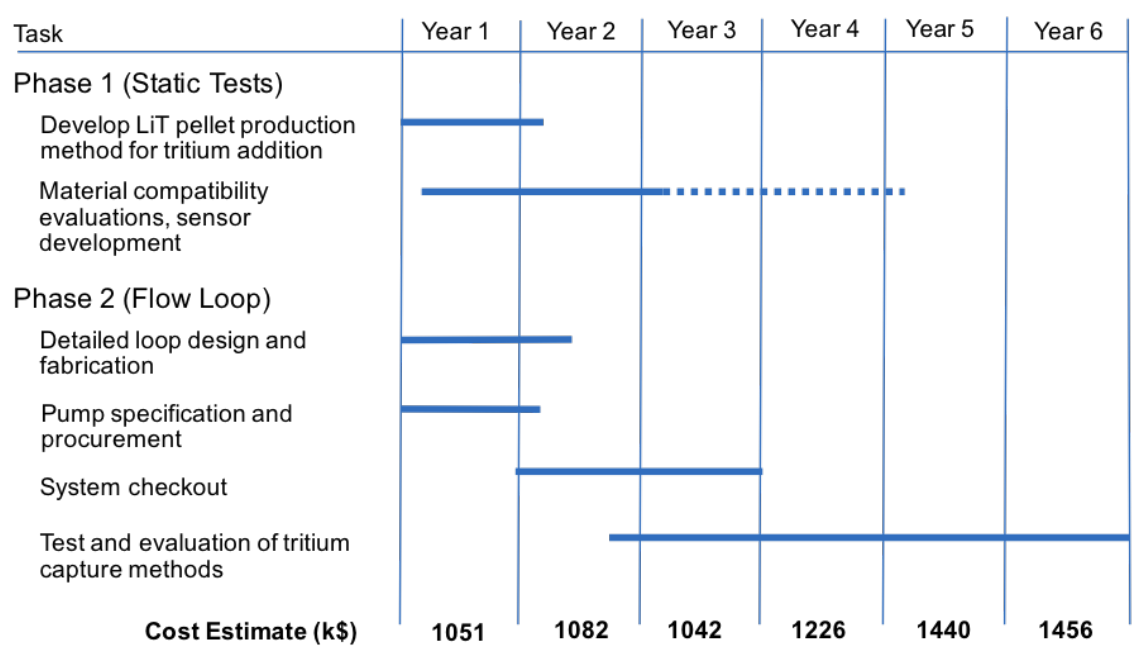

Figure 15. Tritium management project schedule - Phase 1 \& 2.

Key elements in the early part of the schedule will impact the time line. Procurement of a high temperature pump for the flow loop is expected to take 9 to 12 months. Selection and procurement of special materials for the static capsule tests is important for that work to inform the fabrication of test assemblies for the flow loop. Additional funding earlier in the time line could improve the ability to meet the proposed overall schedule. 



\section{SUMMARY}

The results of the Phase 1 and Phase 2 testing will provide the data necessary for design of tritium capture method(s) to be qualified in the engineering scale facility.

Tritium addition methods, and especially the development of LiT pellets, will be directly transferable to the engineering-scale facility. Development of redox control methods and associated measurement techniques will also be a key technology for operating the engineering-scale facility and molten salt reactors in general. The test assemblies evaluated in the ORNL loop will be scalable to the engineering-scale facility and will provide a basis for down-selecting appropriate designs and methods for tritium management.

Modeling of the proposed test loop is being used to size equipment and predict test section performance. Models for the pressure drop of the proposed loop are available to help wth pump procurement. A trace substance model has been developed and verified against simple analytical solutions for predicting tritium transport in the loop. A combined thermal-hydraulic and tritium transport/diffusion model will soon be available which will allow for dynamic modeling of the test loop. Partial validation of the dynamic model is possible by using historical data from [2] with subsequent validation to follow operation of the test loop.

The analysis presented in this report indicates that a molten salt loop test assembly to study tritium transport is feasible. However, the following aspects must be considered in a detailed design, which is the next step, pump design and procurement, materials compatibility, freeze valve development and testing, tritium injection method and testing, redox control of the molten salt, and instrumentation for monitoring of fluoride chemical potential and tritium detection. 



\section{REFERENCES}

\section{References}

[1] J. D. Stempien. Tritium transport, corrosion, and fuel performance modeling in the fluoride salt-cooled high-temperture reactor (FHR). PhD thesis, Massachusetts Institute of Technology, 2015.

[2] G. T. Mays, A. N. Smith, and J. R. Engel. Distribution and behavior of tritium in the coolant-salt technology facility. Technical Report ORNL/TM-5759, Oak Ridge National Laboratory, 1977.

[3] J. L. Holm. Thermodynamic properties of some molten alkali fluoride-beryllium fluoride mixtures. Chemicke Zvesti, 30(6):759-767, 1976.

[4] J. L. Holm and O. J. Kleppa. Enthalpies of mixing in liquid beryllium fluoride-alkali fluoride mixtures. Inorganic Chemistry, 8(2):207-212, 1969.

[5] A. Romero-Serrano, M. Hallen-Lopez, and et al. Thermodynamic analysis of LiF-BeF2 and KF-BeF2 melts by a structural model. Journal of Fluorine Chemistry, 130:336-340, 2009.

[6] M. W. Chase Jr. NIST-JANAF thermochemical tables. Journal of Physical Chemistry Reference Data, 1998.

[7] C. W. Forsberg and et al. Tritium control and capture in salt-cooled fission and fusion reactors: Status, challenges, and path forward. Nuclear Technology, 197(2):119-139, 2017.

[8] P. Calderoni, P. Sharpe, M. Hara, and Y. Oya. Measurement of tritium permeation in flibe (2lif-bef2). Fusion Engineering and Design, 83(7-9):1331-1334, 2008.

[9] D. Ludwig, L. Olson, K. Sridharan, M. Anderson, and T. Allen. High temperature electrochemistry of molten fluoride salt for measurement of dissolved chromium. Corrosion Engineering, Science and Technology, 46(4):360-364, 2011.

[10] C. A. Schroll, S. Chatterjee, T. Levitskaia, W. R. Heineman, and S. A. Bryan. Spectroelectrochemistry of eucl3 in four molten salt eutectics: 3 licl-nacl, 3 licl-2 kcl, licl-rbcl, and 3 licl-2 cscl; at 873k. Electroanalysis, 28(9):2158-2165, 2016.

[11] G. R. Longhurst. Tmap7 user manual. Technical report, Idaho National Engineering and Environmental Laboratory, 2008.

[12] T. Aizawa and et al. Hydrogen adsorption on transition-metal carbide (111) surfaces. Surface Science, 381(2-3):157-164, 1997.

[13] S. T. Tokumitsu, T. Anazawa, and et al. Interaction of hydrogen with $\mathrm{ZrC}(111)$ surface: Angle-resolved photoemission study. Surface Science, 351(1-3):165-171, 1996.

[14] M. Balden and et al. Deuterium retention by implantation in carbide-doped graphites. Physica Scripta, T103:38-42, 2003.

[15] M. Horigome and et al. Impregnation of metal carbides in Raney Ni-PTFE hydrogen electrodes. International Journal of Hydrogen Energy, 32(3):365-370, 2007.

[16] S. R. Sherman and T. M. Adams. Tritium barrier materials and separation systems for the ngnp. Technical Report WSRC-STI-2008-00358, Savannah River National Laboratory, August 2008. 
[17] S. Welte, G. Ana, I. Cristescu, L. Doerr, B. Knutz, J. Konrad, and R. Michling. Construction and commissioing of an iter sized pd/ag permeator for a water detritiation experiment. Fusion Engineering and Design, 84:1969-1972, 2009.

[18] T. Xia, C. He, H. Yang, W. Zhao, L. Yang, and TMT Team. Hydrogen extraction characteristics of high-temperature proton conductor ceramics for hydrogen isotopes purification and recovery. Fusion Engineering and Design, 89:1500-1504, 2014.

[19] H. Borland, L. Llivina, S. Colominas, and J. Abella. Proton conducting ceramics for potentiometric hydrogen sensors for molten metals. Fusion Engineering and Design, 88:2431-2435, 2013.

[20] A. H. McDaniel, E. C. Miller, and et al. Sr- and Mn-doped LaAlO3-delta for solar thermochemical H2 and CO production. Energy E Environmental Science, 6(8):2424-2428, 2013.

[21] A. H. McDaniel, A. Ambrosini, and et al. Nonstoichiometric perovskite oxides for solar thermochemical h-2 and co production. In R. Pitchumani, editor, Proceedings of the Solarpaces 2013 International Conference, volume 49, pages 2009-2018, 2014.

[22] F. Chen. Novel methods of tritium sequestration: high temperature gettering and separation membrane materials discovery for nuclear energy systems. Technical report, NEUP US DOE, 2014.

[23] R. Munkundan, E. L. Brosha, S. A. Birdsell, A. L. Costello, F. H. Garzon, and R. S. Willms. Tritium conductivity and isotope effect in proton-conducting perovskites. Journal of the Electrochemical Society, 146(6):2184-2187, 1999.

[24] G. G. Chang and et al. Control of interpenetration in a microporous metal-organic framework for significantly enhanced $\mathrm{C} 2 \mathrm{H} 2 / \mathrm{CO} 2$ separation at room temperature. Chemical Communications, 52 (17):3494-3496, 2016.

[25] S. J. Nikodemski, J. H. Tong, and et al. Solid-state reactive sintering mechanism for proton conducting ceramics. Solid State Ionics, 253:201-210, 2013.

[26] J. H. Tong, D. Clark, and et al. Solid-state reactive sintering mechanism for large-grained yttrium-doped barium zirconate proton conducting ceramics. Journal of Materials Chemistry, 20(30): 6333-6341, 2010.

[27] J. H. Tong, D. Clark, and et al. Cost-effective solid-state reactive sintering method for high conductivity proton conducting yttrium-doped barium zirconium ceramics. Solid State Ionics, 181 (11-12):496-503, 2010.

[28] G. Yoder and et al. Start-up operation experience with a liquid fluoride salt forced convection loop. Submitted to Nuclear Engineering and Design.

[29] PTC. PTC Mathcad, 2017. URL https://www.ptc.com/en/engineering-math-software/mathcad.

[30] RELAP5-3D Code Development Team. RELAP5-3D code manual volume I: Code structure, system models and solution methods revision 4.3 INL/MIS-15-36723. Technical report, Idaho National Laboratory, 2015.

[31] Applied Programming Technology. Snap, 2017. URL https://www . aptplot.com/snap/index.jsp. 
[32] Modelica Association. Modelica and modelica association, 2017. URL https://modelica.org.

[33] P. W. Humrickhouse and B. J. Merrill. Vacuum permeator analysis for extraction of tritium from DCLL blankets. Fusion Science and Technology, 68(2):295-302, 2015.

[34] R. B. Bird, W. E. Stewart, and E. N. Lightfoot. Transport Phenomena. John Wiley \& Sons. Inc., rev. 2nd edition, 2007.

[35] J. D. Rogers and F. G. Brickwedde. Deuterium and tritium saturated-liquid PVT according to the quantum-mechanical principle of corresponding states. Journal of Chemical Physics, 42(8): 2822-2825, 1965. 

APPENDIX A. Binary Gas Diffusion 



\section{APPENDIX A. Binary Gas Diffusion}

Calculation of the tritium transport rate from the outside of the permeator tubes to the Ar sweep gas requires calculation of the diffusion coefficient of $T_{2}$ in Ar. This is done using kinetic gas theory as described in Bird [34]. The parameters for the binary gas mass diffusion calculation are listed in Table 14. The equation for calculation of the diffusion coefficient, $D_{A B}$, for a mixture of two gases, $\mathrm{A}(\mathrm{Ar}) \& \mathrm{~B}\left(\mathrm{~T}_{2}\right)$, is:

$$
D_{A B}=D_{0} \frac{\sqrt{T^{3}\left(\frac{1}{M_{A}}+\frac{1}{M_{B}}\right)}}{p \sigma_{A B}^{2} \Omega_{A B}\left(\frac{k T}{\varepsilon_{A B}}\right)}
$$

The value of collision diameter $\sigma_{A B}$ is calculated from the arithmetic mean:

$$
\sigma_{A B}=\frac{\sigma_{A}+\sigma_{B}}{2}
$$

The value of the characteristic energy $\varepsilon_{A B}$ is calculated from the geometric mean:

$$
\varepsilon_{A B}=\sqrt{\varepsilon_{A} \varepsilon_{B}}
$$

The value of the collision integral $\Omega_{A B}$ as a function of reduced temperature is calculated from interpolating the table provided in App. E of Bird [34]. In the Modelica calculation, the pressure, $p$, and temperature, $T$, are allowed to vary with time, though the initial calculations are isothermal and isobaric. For example, at $700^{\circ} \mathrm{C}$ and $1 \mathrm{~atm}$ with $\mathrm{Ar}$ and $\mathrm{T}_{2}$, the calculation results in $3.357 \mathrm{~cm}^{2} / \mathrm{s}$.

Table 14. Parameters for binary gas mass diffusion calculation

\begin{tabular}{lcccc}
\hline Parameter & Symbol & Value & Units & Ref. \\
\hline Diffusion constant & $D_{0}$ & $\frac{3}{16 N_{A}} \sqrt{\frac{2 R^{3}}{\pi}}$ & & {$[34]$} \\
Ideal gas constant & $R$ & 8.314 & $\frac{J}{m o l-K}$ & - \\
Avogadro's number & $N_{A}$ & $6.022 x \times 10^{23}$ & $\frac{1}{m g l}$ & - \\
Boltzmann's constant & $k$ & $1.381 \times 10^{-23}$ & $\frac{g}{K}$ & - \\
Molar mass species A & $M_{A}$ & 39.944 & $\mathrm{gm} / \mathrm{mol}$ & - \\
Molar mass species B & $M_{B}$ & 6.032 & $\mathrm{gm} / \mathrm{mol}$ & - \\
Collision diameter species A & $\sigma_{A}$ & 3.418 & $\AA$ & {$[34]$} \\
Collision diameter species B & $\sigma_{B}$ & 2.949 & $\AA$ & {$[35]$} \\
Characteristic energy species A & $\frac{\varepsilon_{A}}{k}$ & 124 & $\mathrm{~K}$ & {$[34]$} \\
Characteristic energy species B & $\frac{\varepsilon_{B}}{k}$ & 34.5 & $\mathrm{~K}$ & {$[35]$}
\end{tabular}



APPENDIX B. Derivation of Axial Tritium Distribution for Molten Salt Application 



\section{APPENDIX B. Derivation of Axial Tritium Distribution for Molten Salt Application}

See below for derivation of axial tritium concentration based on Humrickhouse and Merrill [33].

Radial tritium flux in fluid:

$$
J_{l}=K_{T}\left(C_{B}-C_{w, l}\right)
$$

Wall interface condition:

$$
C_{w, s}=K_{s} \sqrt{\frac{C_{w, l}}{K_{H}}}
$$

Radial tritium flux in solid (from cylindrical solution with vacuum boundary):

$$
J_{s}=\frac{2 D_{s} C_{w, s}}{d \ln \frac{d_{o}}{d}}
$$

Set fluxes equal:

$$
\begin{gathered}
J_{l}=J_{s} \\
K_{T}\left(C_{B}-C_{w, l}\right)=\frac{2 D_{s} C_{w, s}}{d \ln \frac{d_{o}}{d}}
\end{gathered}
$$

Substitute for wall interface condition:

$$
K_{T}\left(C_{B}-C_{w, l}\right)=\frac{2 D_{s} K_{s} \sqrt{\frac{C_{w, l}}{K_{H}}}}{d \ln \frac{d_{o}}{d}}
$$

Solve for $C_{w, l}$ using quadratic equation:

$$
C_{w, l}=C_{B}+\frac{2 \pm 2 \sqrt{C_{B} \xi+1}}{\xi}
$$

Where:

$$
\xi=K_{H}\left(\frac{K_{T} d \ln \frac{d_{o}}{d}}{D_{s} K_{s}}\right)^{2}
$$

Substitute $C_{w, l}$ back into fluid flux:

$$
J_{l}=K_{T}\left[C_{B}-\left(C_{B}+\frac{2 \pm 2 \sqrt{C_{B} \xi+1}}{\xi}\right)\right]
$$


Perform differential mass balance on control volume:

$$
\frac{\partial C_{B}(z)}{\partial z}=-\frac{4}{v d} J_{l}
$$

Replace $J_{l}$ and simplify:

$$
\frac{\partial C_{B}(z)}{\partial z}=\frac{8 K_{T}}{v d \xi}\left(1 \pm \sqrt{\xi C_{B}(z)+1}\right)
$$

Rearrange for solution:

$$
\frac{\partial C_{B}}{1 \pm \sqrt{\xi C_{B}+1}}=\frac{8 K_{T}}{v d \xi} \partial z
$$

Integrate both sides:

$$
\begin{gathered}
\int \frac{8 K_{T}}{v d \xi} \partial z=\frac{8 K_{T} z}{v d \xi}+\text { Const. } \\
\int \frac{1}{1 \pm \sqrt{\xi C_{B}+1}} \partial C_{B}=-\frac{2\left(\ln \left(\sqrt{\xi C_{B}+1} \pm 1\right) \mp \sqrt{\xi C_{B}+1}\right)}{\xi}+\text { Const. }
\end{gathered}
$$

Set equal, cancel out $\xi$ in denominator, then define concentration at $\mathrm{z}=0$ to $C_{0}$ to solve for Const.:

$$
\begin{gathered}
C_{B}(0)=C_{0} \\
-2\left(\ln \left(\sqrt{\xi C_{B}(z)+1} \pm 1\right) \mp \sqrt{\xi C_{B}(z)+1}\right)=\frac{8 K_{T} z}{v d}+\text { Const. } \\
\text { Const. }=-2\left(\ln \left(\sqrt{\xi C_{0}+1} \pm 1\right) \mp \sqrt{\xi C_{0}+1}\right) \\
-2\left(\ln \left(\sqrt{\xi C_{B}(z)+1} \pm 1\right) \mp \sqrt{\xi C_{B}(z)+1}\right)+2\left(\ln \left(\sqrt{\xi C_{0}+1} \pm 1\right) \mp \sqrt{\xi C_{0}+1}\right)=\frac{8 K_{T} z}{v d}
\end{gathered}
$$

By inspection we find that the second solution is correct, yielding as the final result:

$$
-2\left(\ln \left(\sqrt{\xi C_{B}(z)+1}-1\right)+\sqrt{\xi C_{B}(z)+1}\right)+2\left(\ln \left(\sqrt{\xi C_{0}+1}-1\right)+\sqrt{\xi C_{0}+1}\right)=\frac{8 K_{T} z}{v d}
$$

This function does not have a closed form solution for $C_{B}(z)$ and requires an iterative approach to solve at each axial location. 